\title{
Regulation of Melanocortin-4 Receptor Pharmacology by Two Isoforms of Melanocortin Receptor Accessory Protein 2 in Topmouth Culter (Culter alburnus)
}

\author{
Min Tao ${ }^{1,2+}$, Ren-Lei Ji ${ }^{2+}$, Lu Huang ${ }^{1}$, Si-Yu Fan ${ }^{1}$, Ting Liu ${ }^{2}$, Shao-Jun Liu ${ }^{1 *}$ and \\ Ya-Xiong TaO ${ }^{2 \star}$ \\ ${ }^{1}$ State Key Laboratory of Developmental Biology of Freshwater Fish, College of Life Sciences, Hunan Normal University, \\ Changsha, China, ${ }^{2}$ Department of Anatomy, Physiology and Pharmacology, College of Veterinary Medicine, Auburn \\ University, Auburn, AL, United States
}

OPEN ACCESS

Edited by: Honoo Satake,

Suntory Foundation for Life

Sciences, Japan

Reviewed by:

Robert M. Dores,

University of Denver, United States

Yajun Wang,

Sichuan University, China

${ }^{*}$ Correspondence:

Shao-Jun Liu

Isj@hunnu.edu.cn

Ya-Xiong Tao

taoyaxi@auburn.edu

†These authors have contributed equally to this work

Specialty section: This article was submitted to Experimental Endocrinology, a section of the journal Frontiers in Endocrinology

Received: 14 May 2020

Accepted: 02 July 2020

Published: 14 August 2020

Citation:

Tao M, Ji R-L, Huang L, Fan S-Y, Liu T, Liu S-J and Tao Y-X (2020) Regulation of Melanocortin-4 Receptor Pharmacology by Two Isoforms of Melanocortin Receptor Accessory Protein 2 in Topmouth Culter (Culter alburnus). Front. Endocrinol. 11:538.

doi: 10.3389/fendo.2020.00538
Melanocortin-4 receptor (MC4R) plays important roles in regulation of multiple physiological processes, and interaction of MC4R and melanocortin receptor accessory protein 2 (MRAP2) is suggested to play pivotal role in energy balance of vertebrates. Topmouth culter (Culter alburnus) is an economically important freshwater fish in China. Herein we cloned culter mc4r, mrap2a, and mrap2b. Culter mc4r consisted of a 981 bp open reading frame encoding a protein of 326 amino acids. qRT-PCR revealed that $m c 4 r$, mrap2a, and mrap2b were primarily expressed in the central nervous system. In the periphery, $m c 4 r$ and mrap2b were expressed more widely in the male, while mrap2a was expressed more widely in the female. Culter MC4R could bind to four peptide agonists and increase intracellular CAMP production dose dependently. Culter MC4R was constitutively active in both CAMP and ERK1/2 pathways, which was differentially regulated by culter MRAP2a and MRAP2b. Culter MRAP2a significantly increased $B_{\max }$ and decreased agonist-stimulated cAMP, while MRAP2b increased cell surface and total expression but did not affect $\mathrm{B}_{\max }$ and agonist-stimulated cAMP. These results will aid the investigation of the potential physiological processes that MC4R might be involved in topmouth culter.

Keywords: topmouth culter, melanocortin-4 receptor, melanocortin receptor accessory protein 2, signaling, constitutive activity

\section{INTRODUCTION}

The melanocortins are derived from tissue-specific post-translational processing of proopiomelanocortin (POMC), including $\alpha-, \beta-, \gamma$-melanocyte-stimulating hormones $(\alpha-$, $\beta-, \gamma-\mathrm{MSH})$ and adrenocorticotropic hormone $(\mathrm{ACTH})(1,2)$. The physiological functions of these peptides are exerted by five melanocortin receptors (MC1R-MC5R), members of rhodopsin-like Family A G-protein-coupled receptors (GPCRs), including regulation of pigmentation, adrenal steroidogenesis, energy homeostasis, lipolysis, stress, cardiovascular, and sexual function (3-5). MC4R is highly expressed in the central nervous system and involved in regulating energy homeostasis via modulating both food intake and energy expenditure; it is also involved in 
regulating sexual function and reproduction by affecting the secretion of reproductive hormones [reviewed in $(6,7)$ ]. Targeted deletion of $M c 4 r$ increases food intake and decreases energy expenditure, resulting in obesity in mice $(8,9)$. MC4R mutation is the leading cause of human monogenic obesity (10) [reviewed in $(11,12)]$.

The MC4R is primarily coupled to the stimulatory heterotrimeric G protein (Gs). MC4R activation leads to stimulation of adenylyl cyclase activity, which will increase the intracellular level of the second messenger cyclic adenosine monophosphate (cAMP) to trigger downstream signaling (13). MC4R activation also phosphorylates extracellular signal-regulated kinase 1 and 2 (ERK1/2) (14-17).

Melanocortin receptor accessory proteins (MRAPs, including MRAP1 and MRAP2), small single transmembranedomain proteins, are identified as receptor-specific molecular chaperones, regulating $\mathrm{MC} 2 \mathrm{R}$ trafficking, ligand binding and cAMP generation (18-21). MRAP2 is involved in modulating energy homeostasis due to its high expression in central nervous system. MRAP2 deceases agonist-stimulated signaling but does not affect basal signaling of human (h) MC4R (20), while MRAP2 in mice decreases the basal activity and increases maximal response $\left(\mathrm{R}_{\max }\right)$ (22). MRAP2 mutations were shown to be potentially pathogenic for early-onset obesity $(22,23)$. Mice with whole body and brain-specific deletion of Mrap2 also have early-onset severe obesity (22). These results suggest that MRAP2 is involved in MC4R signaling and regulating body weight in mammals $(21,22)$.

MC4R has also been characterized in teleosts $(21,24-$ 32 ), and shown to act as a regulator in energy balance, sexual behavior, and reproduction (33-37). Non-mammalian MRAPs are different from those of mammals. Some fishes only have MRAP2, lacking MRAP1 $(38,39)$, and some have two MRAP2s (MRAP2a and MRAP2b) (21, 40). In zebrafish, two MRAP2s have different expression patterns at different stages, with MRAP2a expressed from embryos to adults, stimulating growth by blocking MC4R action in larvae, and MRAP2b mainly expressed in adults, enhancing MC4R response (21). In vitro, MRAP2a decreases the MC4R affinity for $\alpha-\mathrm{MSH}$, but MRAP2b increases ligand sensitivity of zebrafish MC4R (21). Hence, a better understanding of the vital functions of MC4R in modulating energy homeostasis and reproductive function and the interaction between MRAP2 and MC4R is important for feeding and artificial breeding of economical species.

The topmouth culter (Culter alburnus), which belongs to Cyprinidae, Cultrinae, Erythroculter, is an economically important freshwater fish widely distributed in large rivers, reservoirs, and lakes in China (41-44). With excellent taste, rapid growth, and strong performance in culture, this fish has been extensively cultured over the past few decades due to high market demand (45). In this study, we cloned culter mc4r, mrap $2 a$, and mrap $2 b$, and investigated the tissue distribution of these genes. We then studied the pharmacological properties of caMC4R and the effects of MRAP2a and MRAP2b on caMC4R.

\section{MATERIALS AND METHODS}

\section{Ligands and Plasmids}

$\left[\mathrm{Nle}^{4}, \quad \mathrm{D}-\mathrm{Phe}^{7}\right]-\alpha-\mathrm{MSH} \quad$ (NDP-MSH) was purchased from Peptides International (Louisville, KY, USA), human $\alpha^{-}$and $\beta$-MSHs from $\mathrm{Pi}$ Proteomics (Huntsville, AL, USA), ACTH (1-24) from Phoenix Pharmaceuticals (Burlingame, CA, USA), and THIQ (N[(3R)-1,2,3,4-Tetrahydroisoquinolinium-3-ylcarbonyl]-(1R)-1(4-chlorobenzyl)-2-[4-cyclohexyl-4-(1H-1,2,4-triazol-1-ylmethy 1)piperidin-1-yl]-2-oxoethylamine) (46) from Tocris Bioscience (Ellisville, MO, USA). We analyzed culter pomc from culter genome, and found that homology of culter $\alpha-\mathrm{MSH}$, ACTH (1-24) and $\beta$-MSH with human counterparts were 100, 87.5, and $57.1 \%$, respectively (Supplementary Figure 1). $\left[{ }^{125} \mathrm{I}\right]-\mathrm{NDP}-\mathrm{MSH}$ and $\left[{ }^{125} \mathrm{I}\right]$-cAMP were iodinated using chloramine $\mathrm{T}$ method $(17,47)$. The N-terminal c-myc-tagged wild-type hMC4R was subcloned into pcDNA3.1 vector as previously described (48). $\mathrm{N}$-terminal c-myc-tagged caMC4R, N-terminal FLAG-tagged caMRAP2a, and N-terminal FLAG-tagged caMRAP2b were synthesized and subcloned into pcDNA3.1 vector by GenScript (Piscataway, NJ, USA) to obtain the expression plasmids.

\section{Gene Cloning and Sequence Alignment}

Adult culter were collected from Engineering Research Center of Polyploid Fish Reproduction and Breeding of the Ministry of Education at Hunan Normal University. Fish were anesthetized before decapitation and tissues were excised and stored at $-80^{\circ} \mathrm{C}$. All experiments were approved by Animal Care Committee of Hunan Normal University and followed guidelines of the Administration of Affairs Concerning Experimental Animals of China.

Total RNA was purified using Trizol ${ }^{\mathrm{TM}}$ Reagent (Invitrogen, Carlsbad, CA, USA). PrimeScript RT reagent kit with gDNA Eraser (TaKaRa, Tokyo, Japan) was used for first-strand cDNA synthesis. Primer Premier 5.0 was used to design specific primers (Supplementary Table 1) to obtain partial cDNA fragment of the coding region and untranslated region (UTR) by PCR and touch-down PCR with TaKaRa LA Taq ${ }^{\circledR}$ (TaKaRa), respectively. PCR products were detected with $1.2 \%$ agarose gels. Target fragments were purified by SanPrep Column DNA Gel (Sangon Biotech, Shanghai, China), and then subcloned into the pMD18-T vector (TaKaRa), and sequenced (Sangon Biotech).

\section{Tissue Distribution of $m c 4 r$, mrap2a, and mrap2b}

To analyze tissue distribution of these genes, the olfactory bulb, telencephalon, mesencephalon, medulla, cerebellum, pituitary, hypothalamus, liver, heart, head kidney, gonads, skin, kidney, muscle, spleen, and gill, were taken from three males and three females, respectively. qRT-PCR was carried out by a Prism 7,500 Sequence Detection System (ABI, Foster City, CA, USA) according to manufacturer's instructions. Primers were designed by AlleleID 6, and $\beta$-actin was used as the internal control (Supplementary Table 1). The reaction consisted of $5 \mu \mathrm{L}$ SYBR 
green PCR Master Mix, $3 \mu \mathrm{L}$ water, $1 \mu \mathrm{L}$ cDNA sample, $0.5 \mu \mathrm{L}$ QPCR-x-F, and $0.5 \mu \mathrm{L}$ QPCR-x-R. The condition was: $50^{\circ} \mathrm{C}$ for $2 \mathrm{~min}, 95^{\circ} \mathrm{C}$ for $10 \mathrm{~min}$, followed by 40 cycles at $95^{\circ} \mathrm{C}$ for $15 \mathrm{~s}$ and $61^{\circ} \mathrm{C}$ for $45 \mathrm{~s}$. To ensure the accuracy, experimental samples were added to a 96 -well plate repeated thrice. The $2^{-\Delta \Delta C T}$ method was used for analyzing the relative expression of the genes (49).

\section{Cell Culture and Transfection}

Human embryonic kidney (HEK) 293T cells (ATCC, Manassas, VA, USA) were cultured at $37^{\circ} \mathrm{C}$ in a $5 \% \mathrm{CO}_{2}$-humidified atmosphere. The medium contained Dulbecco's Modified Eagle's medium (DMEM) (Invitrogen, Carlsbad, CA, USA), 10\% newborn calf serum, $10 \mathrm{mM}$ HEPES, $50 \mu \mathrm{g} / \mathrm{mL}$ of gentamicin, $0.25 \mu \mathrm{g} / \mathrm{mL}$ of amphotericin B, $100 \mu \mathrm{g} / \mathrm{mL}$ of streptomycin and $100 \mathrm{IU} / \mathrm{mL}$ of penicillin. Cells were plated into 24 -well or 6-well plates (Corning, NY, USA) pre-coated with $0.1 \%$ gelatin. At $\sim 60-$ $70 \%$ confluency, cells were transfected with plasmids by calcium phosphate precipitation method (50). Total DNA was normalized using empty vector pcDNA3.1.

\section{Flow Cytometry Assay}

The influence of caMRAP2a or caMRAP2b on the cell surface and total expression levels of caMC4R was studied using flow cytometry as described earlier (31). Cells were plated into 6well plates and transfected with caMC4R (N-terminal c-myc tag) and caMRAP2a or caMRAP2b plasmids in four ratios $(1: 0,1: 1$, 1:3, and 1:5). The C6 Accuri Cytometer (Accuri Cytometers, Ann Arbor, MI, USA) was used for analysis. The empty vector (pcDNA3.1) fluorescence was used for background staining. The expression of the caMC4R was calculated as the percentage of 1:0 (caMC4R/caMRAP2a or caMC4R/caMRAP2b) group (51).

\section{Ligand Binding Assays}

Binding assay was used to study the binding properties of caMC4R to different ligands as described previously $(48,52)$. Culter MC4R or hMC4R plasmid $(0.25 \mu \mathrm{g} / \mu \mathrm{L})$ were transfected into cells (6-well plate). The ligands and final concentrations were: NDP-MSH (from $10^{-11}$ to $10^{-6} \mathrm{M}$ ), $\beta$-MSH (from $10^{-10}$ to $10^{-5} \mathrm{M}$ ), $\alpha$-MSH (from $10^{-10}$ to $10^{-5} \mathrm{M}$ ), ACTH(1-24) (from $10^{-10}$ to $10^{-5} \mathrm{M}$ ) or THIQ (from $10^{-11}$ to $10^{-6} \mathrm{M}$ ). To study the effects of caMRAP2a or caMRAP2b on the binding property of caMC4R, caMC4R $(0.25 \mu \mathrm{g} / \mu \mathrm{L})$ with caMRAP2a or caMRAP2b in two ratios (1:0 and 1:5) were transfected into cells (6-well plate), and two ligands, $\alpha$-MSH (from $10^{-10}$ to $10^{-5} \mathrm{M}$ ) and $\operatorname{ACTH}(1-24)$ (from $10^{-10}$ to $10^{-5} \mathrm{M}$ ) were used.

\section{cAMP Assays}

Radioimmunoassay for intracellular cAMP was performed as described previously $(47,48)$. The final concentration of ligands used for signaling assays were NDP-MSH (from $10^{-11}$ to $10^{-6}$ $\mathrm{M}$ ), $\alpha$-MSH (from $10^{-10}$ to $10^{-5} \mathrm{M}$ ), $\beta$-MSH (from $10^{-10}$ to $10^{-5}$ $\mathrm{M}$ ), $\mathrm{ACTH}(1-24)$ (from $10^{-10}$ to $10^{-5} \mathrm{M}$ ), or THIQ (from $10^{-10}$ to $\left.10^{-5} \mathrm{M}\right)$.

To study the potential effect of caMRAP2a and caMRAP2b on caMC4R signaling, caMC4R $(0.25 \mu \mathrm{g} / \mu \mathrm{L})$ and caMRAP2a or caMRAP2b plasmids in two ratios (1:0 and 1:5) were cotransfected into cells (24-well plate), and two ligands, $\alpha-\mathrm{MSH}$ (from $10^{-10}$ to $10^{-5} \mathrm{M}$ ) and $\mathrm{ACTH}(1-24)$ (from $10^{-10}$ to $10^{-5}$ $\mathrm{M})$ were used. To study the dose-dependent effect of caMRAP2a or caMRAP $2 b$ on the $\mathrm{R}_{\max }$ of cAMP levels to $\alpha-\mathrm{MSH}$ stimulation, caMC4R $(0.25 \mu \mathrm{g} / \mu \mathrm{L})$ and caMRAP2a or caMRAP2b plasmids in four ratios (1:0, 1:1, 1:3 and 1:5) were co-transfected into cells (24-well plate). To explore the constitutive activity of GscAMP, cells were transfected with caMC4R plasmid in different concentrations $(0,0.007,0.015,0.030,0.060,0.125$, and 0.250 $\mu \mathrm{g} / \mu \mathrm{L})$ (6-well plate).

\section{ERK1/2 Phosphorylation Assay}

To explore the constitutive pERK1/2 level, cells were transfected with caMC4R plasmid in different concentrations $(0,0.007$, $0.015,0.030,0.060,0.125$, and $0.250 \mu \mathrm{g} / \mu \mathrm{L})$. The phosphorylated ERK1/2 levels were detected as described previously $(16,17) . \alpha-$ MSH $\left(10^{-6} \mathrm{M}\right)$ was used for stimulation. Rabbit anti-pERK1/2 antibody (Cell Signaling Technology, Danvers, MA) and mouse anti- $\beta$-tubulin antibody (Developmental Studies Hybridoma Bank, University of Iowa, Iowa City, IA) were used in this study. ImageJ 1.44 software (National Institute of Health, Bethesda, $\mathrm{MD})$ were used to quantify the films. The pERK1/2 levels were normalized as a ratio of pERK1/2 over $\beta$-tubulin in the same gel.

\section{Statistical Analysis}

All data were shown as mean \pm SEM. Prism 8.3 software (GraphPad, San Diego, CA, USA) was used to calculate parameters including maximal binding $\left(\mathrm{B}_{\max }\right), \mathrm{IC}_{50}$, maximal response $\left(\mathrm{R}_{\max }\right)$, basal activity, and $\mathrm{EC}_{50}$. The significance of differences in ligand binding and signaling between caMC4R and hMC4R were determined by Student's $t$-test. Ligand binding, cAMP, flow cytometry parameters of caMC4R regulated by MRAP2s and ERK1/2 signaling were analyzed for significance of differences by one-way ANOVA. Statistical analysis was also performed with GraphPad Prism 8.3 software.

\section{RESULTS}

\section{Nucleotide and Deduced Amino Acid Sequences of caMC4R, caMRAP2a and caMRAP2b}

The cloned topmouth culter $m c 4 r$ had 981 bp open reading frame (ORF) that encoded a putative protein of 326 amino acids with $36.57 \mathrm{kDa}$ molecular mass (Figure 1A). The culter MC4R had seven putative hydrophobic transmembrane domains (TMDs) with an extracellular N-terminus, three extracellular loops (ECLs), three intracellular loops (ICLs), and an intracellular C-terminus (Figure 1A and Supplementary Figure 2). The deduced amino acid sequence in the TMDs of caMC4R was significantly conserved with those of other species. The PMY, DRY, and DPxxY motifs were predicted at homologous positions with MC4Rs of other species (Supplementary Figure 2). Two potential $\mathrm{N}$-linked glycosylation site $\left(\mathrm{Asn}^{2}\right.$ and $\mathrm{Asn}^{15}$ ) in $\mathrm{N}$ terminus, 15 cysteine residues and consensus sequence for protein kinase $\mathrm{C}$ phosphorylation $\left(\mathrm{Thr}^{310} \mathrm{Phe}^{311} \mathrm{Lys}^{312}\right.$ ) in Cterminus were observed in the caMC4R primary structure (Supplementary Figure 2). By multiple sequence alignment analysis, we found that caMC4R shared high identities with other 
A

1 ATG AAC ACC TCA CAT CAT CAT GGA CTG CAT CAT TTG TAC CGG AAT CAC AGC CAG GGA GCT 60

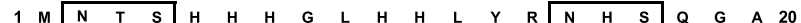
61 CTG CCG GTG GGA AAG CCT GAT CAG GTT GAG AGA GGA TCA GCC TCT GGA TGC TAT GAG CAG 120 $\begin{array}{llllllllllllllllllllllll}21 & L & P & V & G & K & P & D & Q & V & E & R & G & S & A & S & G & C & Y & E & Q & 40\end{array}$ 121 CTG CTC ATC TCC ACA GAG GTC TTC CTC ACG CTC GGG CTT GTC AGT CTC CTG GAG AAC ATT 180 $\begin{array}{llllllllllllllllllllll}41 & \text { L } & \text { L } & \text { I } & \text { S } & \text { T } & \text { E } & \text { V } & \text { F } & \text { L } & \text { T } & \text { L } & G & \text { L } & \text { V } & \text { S } & \text { L } & \text { L } & E & \text { N } & \text { I } & 60\end{array}$ 181 CTG GTG ATT GCT GCT ATT GTC AAG AAC AAG AAC CTT CAT TCT CCC ATG TAT TTC TTT ATC 240 $\begin{array}{llllllllllllllllllllllllll}61 & L & V & \text { I } & A & A & I & V & K & N & K & N & L & H & S & P & M & Y & F & F & I & 80\end{array}$ 241 TGC AGT TTA GCC GTA GCA GAC TTG TTG GTC AGT GTC TCC AAT GCT TCA GAA ACG GTC GTG 300 $\begin{array}{lllllllllllllllllllllll}81 & C & S & L & A & V & A & D & L & L & V & S & V & S & N & A & S & E & T & V & V & 100\end{array}$ 301 ATG GCG CTC ATC ACG GGG GGC AAC CTG ACC AAC CGC GAG AGC ATC ATC AAG AAC ATG GAC 360 $\begin{array}{llllllllllllllllllllllll}101 & M & A & L & \text { I } & \text { T } & G & G & \text { N } & \text { L } & \text { T } & \text { N } & \text { R } & \text { E } & \text { S } & \text { I } & \text { I } & \text { K } & \text { N } & M & \text { D } & 120\end{array}$ 361 AAC GTT TTT GAC TCG ATG ATC TGC AGC TCG CTT TTA GCC TCC ATT TGG AGT TTG TTG GCC 420 $\begin{array}{lllllllllllllllllllllll}121 & N & V & F & D & S & M & \text { I } & C & S & S & L & L & A & S & \text { I } & \text { W } & S & L & L & A & 140\end{array}$ 421 ATC GCG GTG GAC CGG TAC ATC ACA ATA TTC TAC GCC TTG CGC TAC CAC AAC ATC ATG ACC 480 $\begin{array}{llllllllllllllllllllllll}141 & \text { I } & A & V & D & R & Y & \text { I } & T & \text { I } & \text { F } & \text { Y } & \text { A } & \text { L } & R & \text { Y } & \text { H } & \text { N } & \text { I } & \text { M } & \text { T } & 160\end{array}$ 481 CAG CGG AGG GCA GGA ACC ATC ATA ACC TGC ATC TGG ACC TTC TGC ACG GTC TCC GGT GTG 540 $\begin{array}{llllllllllllllllllllll}161 & Q & R & R & A & G & T & \text { I } & \text { I } & T & C & \text { I } & \text { W } & T & F & C & T & V & S & G & V & 180\end{array}$ 541 CTC TTT ATT GTG TAC TCG GAG AGC ACC ACC GTT CTC ATC TGC CTT ATT AGC ATG TTC TTC 600 $\begin{array}{llllllllllllllllllllllll}181 & L & F & \text { I } & V & Y & S & E & S & T & T & V & L & \text { I } & C & L & \text { I } & S & M & F & F & 200\end{array}$ 601 ACC ATG TTG GCT CTC ATG GCC TCG CTC TAT GTC CAC ATG TIT CTT CTA GCC CGG CTG CAC 660 $\begin{array}{lllllllllllllllllllllll}201 & \text { T } & M & L & \text { A } & \text { L } & M & \text { A } & S & \text { L } & \text { Y } & \text { V } & \text { H } & \text { M } & \text { F } & \text { L } & \text { L } & \text { A } & \text { R } & \text { L } & \text { H } & 220\end{array}$ 661 ATG AAG CGC ATT GCT GCC CTC CCT GGC AAT GGC CCT ATC TGG CAG GCA GCA AAT ATG AAG 720

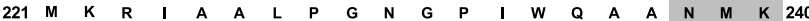
721 GGG GCC ATC ACC ATC ACT ATC CTG CTG GGG GTA TTT GTA GTG TGC TGG GCT CCC TTT TTC 780 $\begin{array}{llllllllllllllllllllll}241 & G & A & I & T & \text { I } & T & \text { I } & L & L & G & V & F & V & V & C & W & A & P & F & F & 260\end{array}$ 781 TTG CAC CTC ATC CTC ATG ATC TCC TGC CCC CGG AAC CCC TAC TGC ATC TGC TTT ATG TCT 840 $\begin{array}{lllllllllllllllllllllll}261 & L & H & L & \text { I } & L & M & \text { I } & S & C & P & R & N & P & Y & C & \text { I } & C & F & M & S & 280\end{array}$ 841 CAT TTC AAC ATG TAT CTG ATA CTC ATT ATG TGC AAC TCA GTC ATA GAC CCT CTC ATC TAT 900 $\begin{array}{llllllllllllllllllllll}281 & H & F & N & M & Y & L & I & L & I & M & C & N & S & V & I & D & P & L & I & Y & 300\end{array}$ 901 GCC TTC AGG AGC CAA GAG ATG AGG AAG ACC TTC AAG GAG ATC TGC TGC TGC TGG TAT GGA 960 $\begin{array}{llllllllllllllllllllll}301 & A & F & R & S & Q & E & M & R & K & T & F & K & E & \text { I } & C & C & C & W & Y & G & 320\end{array}$ 961 CTG ACC TCT CTA TGT GTA TAA 321 L T S L C V *

\section{B}

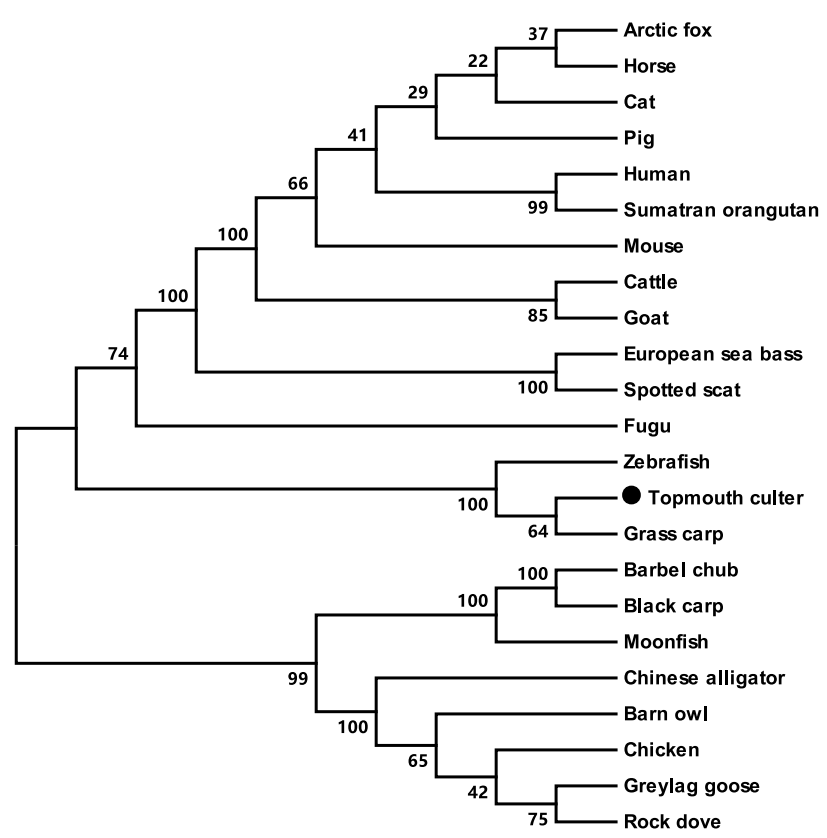

FIGURE 1 | Nucleotide and deduced amino acid sequences and phylogenetic tree of caMC4R. (A) Nucleotide and deduced amino acid sequences of caMC4R. Positions of nucleotide and amino acid sequences are indicated on both sides. Shaded boxes denote putative TMD1-7. Potential phosphorylation sites are present in oval frame. Underline show PMY, DRY, DPxxY motifs. Open boxes denote the consensus sequence for $N$-linked glycosylation sites. Asterisk (*) indicates stop codon. (B) Phylogenetic tree of MC4R proteins. The tree was constructed by the neighbor-joining (NJ) method. Numbers at nodes indicate the bootstrap value, as percentages, obtained for 1,000 replicates. Black dot shows caMC4R. MC4Rs: Culter alburnus (topmouth culter, MT163518), Scatophagus argus (spotted scat, KU760724.1), Dicentrarchus labrax (European sea bass, CBN82190.1), Lepisosteus oculatus (spotted gar, XP_006634516.1), Danio rerio (zebrafish, NP_775385.1), Vulpes lagopus (arctic fox, ACN55093.1), Ctenopharyngodon idella (grass carp, AOZ60534.1), Paralichthys olivaceus (Japanese flounder, ADP09415.1),

Squaliobarbus curriculus (barbel chub, ADV40875.1), Takifugu rubripes (fugu, NP_001027732.1), Mylopharyngodon piceus (black carp, ADV40871.1), Tyto alba (barn owl, ATN96237.1), Columba livia (rock dove, XP_021153678.1), Bos taurus (cattle, NP_776535.1), Alligator sinensis (Chinese alligator, XP_006025279.1), Anser anser (greylag goose, ABF19809.1), Pongo abelii (Sumatran orangutan, XP_002828309.1), Equus caballus (horse, XP_001489706.1), Felis catus (cat, XP_019670932.2), Gallus gallus (chicken, AEP17334.10), Sus scrofa (pig, ABD28176.1), Mus musculus (mouse, NP_058673.2), Capra hircus (goat, NP_001272520.1), and Homo sapiens (human, NP_005903.2).

piscine MC4Rs, with $99.1 \%$ homology to grass carp, $98.5 \%$ to zebrafish, $86.9 \%$ to flounder, $87.7 \%$ to fugu, and $87.5 \%$ to sea bass, as well as to mammalian MC4Rs with $81.4 \%$ to human, $81.2 \%$ to mouse, and $82.0 \%$ to pig. Phylogenetic tree between caMC4R and other MC4Rs revealed that caMC4R was localized in a clade of grass carp and zebrafish (Figure 1B).

The cloned culter mrap $2 a$ had 654 bp ORF that encoded a putative protein of 217 amino acids with $24.37 \mathrm{kDa}$ molecular mass (Figure 2A). The cloned culter mrap $2 b$ had 594 bp ORF that encoded a putative protein of 197 amino acids with $22.20 \mathrm{kDa}$ molecular mass (Figure 2B). The culter MRAP2a and MRAP2b had similar features to other MRAP2s that contained a potential $N$-linked glycosylation site (Asn ${ }^{8}$ of caMRAP2a and $A^{2} n^{6}$ of caMRAP2b) in N-terminus, a single TMD, and a long C-terminal tail with many conserved residues (Supplementary Figure 3). In addition, a putative motif (LKAHKYS) was also found in caMRAP2a and caMRAP2b (Supplementary Figure 3), which is vital in the formation of antiparallel homodimers (53). Multiple sequence alignment showed that caMRAP2a shared high identity (93.6\%) with zebrafish MRAP2a, and low identities (61.0\%) with
caMRAP2b and other piscine MRAP2, with $64.4 \%$ to rainbow trout MRAP2, 60.9\% to tilapia MRAP2, as well as to mammalian MRAP2s with $61.8 \%$ to human MRAP2, $62.2 \%$ to mouse MRAP2 and $60.3 \%$ to goat MRAP2. Similar to caMRAP2a, caMRAP2b shared high identity with zebrafish MRAP2b with $80.9 \%$, and low identities with other piscine MRAPs, with $61.1 \%$ to rainbow trout MRAP2, 59.0\% to tilapia MRAP2, as well as to mammalian MRAP2s with $58.3 \%$ to human, $60.1 \%$ to mouse and $57.7 \%$ to goat. Phylogenetic tree analysis showed that caMRAP2a was clustered with teleost MRAP2a, nested with zebrafish MRAP2a, and MRAP2b was clustered with teleost MRAP2b, nested with kanglang fish MRAP2b (Figure 2C).

\section{Tissue Expression of Culter mc4r, mrap2a, and $m$ rap2b}

The relative mRNA expression of culter mc4r, mrap $2 a$, and mrap $2 b$ was analyzed by qRT-PCR (Figure 3). Sexual dimorphism was observed in mc4r expression (Figures 3A,B). Our results showed that in the male culter, $m c 4 r$ was expressed more widely, in brain (telencephalon, mesencephalon, 
A

1 ATG CCG AGG TTC CAG TTT TTA AAC AGT ACT AGT ATG CCA AAT CAT AAT TAT GAA TGG AGC 60

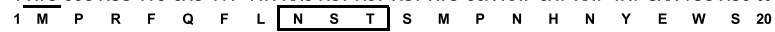
61 TAC GAA TAC TAC GAC GAC GAA GAG CCC GTG TCT TTT GAA GGA CTC AAA GCA CAT CGA TAT 120 $\begin{array}{llllllllllllllllllllllll}21 & Y & E & Y & Y & D & D & E & E & P & V & S & F & E & G & L & K & A & H & R & Y & 40\end{array}$ 121 TCC ATT GTG ATT GGC TTC TGG GTG GGT CTT GCA GTT TTT GTC ATA TTT ATG TTT TTT GTT 180 $\begin{array}{llllllllllllllllllllll}41 & S & \text { I } & V & \text { I } & G & F & W & V & G & L & A & V & F & V & I & F & M & F & F & V & 60\end{array}$ 181 CTG ACT CTT CTG ACC AAA ACA GGA GCC CCA CAC CCA GAG GCC GCG GAG CCT TAC GAG AAA 240 $\begin{array}{llllllllllllllllllllllll}61 & L & T & L & L & T & K & T & G & A & P & H & P & E & A & A & E & P & Y & E & K & 80\end{array}$ 241 CGG ATG CGT CTC ACC AGC TGC GCC GAG GGT CTG GGG CGC CAA CGT GAG GCG GAC ACC CGA 300 $81 R M A$ 301 ACG GCT CTC TCC CGC CCA TTG CTG GAG GAG TCC CGG TCT CTT TTT CAC TGT TAT ATT AAT 360 301 ACG GGT CTC TCC CGC CCA TTG CTG GAG GAG TCC CGG TCT CTT TIT CAC TGT TAT ATT AAT 360 101 T L 361 GAA GAA GAG CGA GAT GGA GGC CGG GTA ACG AGC AAC GCT GGC GGT GCC GCC CAC GGA CGT 420 421 ACG GGC AGC GGC AAC TCA AGA GAA CAG GTG GAA GCG GTC GGC CTT GTC GTC CAA AGC ATG 480

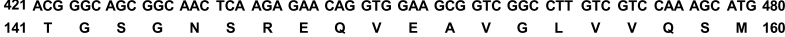

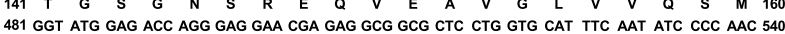

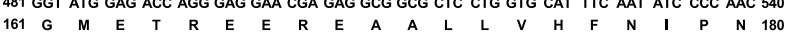
$\begin{array}{llllllllllllllllllllll}161 & G & M & E & T & R & E & E & R & E & A & A & L & L & V & H & F & N & I & P & \text { N } & 180 \\ 541 & \text { TTT GTG AAC } & \text { TCA GAA TTG AGC }\end{array}$

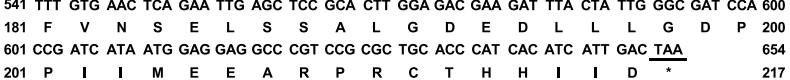
$\begin{array}{llllllllllllllllllllll}201 & \text { P } & \text { I } & \text { I } & \text { M } & \text { E } & \text { E } & \text { A } & \text { R } & \text { P } & \text { R } & \text { C } & \text { T } & \text { H } & \text { H } & \text { I } & \text { I } & \text { D } & \text { * }\end{array}$

\section{B}

1 ATG ACT GAA TAT TCA AAC CAC AGT CAG TCC GCT GGA GAT TAT GAG TGG CAT TAT GAA TAC 60 \begin{tabular}{llllll|lll|lllllllllllll}
1 & $M$ & $T$ & $E$ & $Y$ & $S$ & $N$ & $H$ & $S$ & $Q$ & $S$ & $A$ & $G$ & $D$ & $Y$ & $E$ & $W$ & $H$ & $Y$ & $E$ & $Y$ & 20
\end{tabular} 61 TAT GAT GAC GAG GAG CCC GTG TCC TTC GAG GGA CTG AGA GCA AAC AGA TAC TCT ATC GTG 120 21 Y D D E E P V S F E G L R A N R Y S I V 40 121 ATT GGT TTC TGG GTC GGA CTG GCT GTG TTC GTC ATC TTT ATG TTC TTT GTT TTG ACC CTG 180

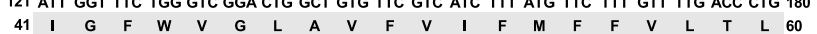
$\begin{array}{cccccccccccccccccccccc}41 & I & G & F & W & V & G & L & A & V & F & V & I & F & M & F & F & V & L & T & \text { L } & 60 \\ 181 & \text { ATT } & \text { ACT } & \text { AAA } & \text { ACT } & \text { GGA } & \text { GCT } & \text { CCA } & \text { CAT } & \text { CCA } & \text { GAG } & \text { ATC } & \text { CCT } & \text { GAC } & \text { CCG } & \text { AGA } & \text { GAA AAG } & \text { CAT CAT } & \text { GGT } & 240\end{array}$

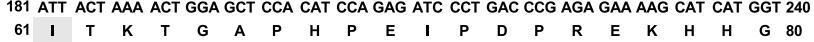
241 CTA GGT GAC TGT GTG CTG GAG GTC GGC GGC TCT CAG GCC TTT TCT CTC CCG CCG CTG CCG 300 $\begin{array}{llllllllllllllllllllll}81 & L & G & D & C & V & L & E & V & G & G & S & Q & A & F & S & L & P & P & L & P & 100\end{array}$ 301 GAT GAA TCA CGT TCC CTC TTT CAC TTC TAC ATC CAC GAG GAG GAA CAA GCC AAA GCC GAC 360 $\begin{array}{llllllllllllllllllllllll}101 & D & E & S & R & S & L & F & H & F & Y & \text { I } & \text { H } & E & E & E & Q & A & K & A & D & 120\end{array}$ 361 AGA GAT GCT GTG ATT GGC AGA GGG AGG CGT TGT GGG CGG GCC TCT GCT GGA CTC CGC CTC 420

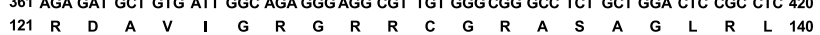
421 CAG GGG ACG ACA GAC GAA GAC GAG CAC TTC CTG TCC AAC TTC AAC ATT CCA AAC TTT GTG 480

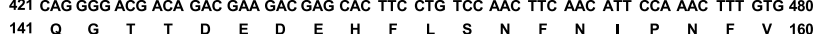
$\begin{array}{llllllllllllllllllllll}141 & Q & G & T & T & D & E & D & E & H & F & \text { L } & \text { S } & \text { N } & F & N & \text { I } & P & \text { N } & \text { F } & \text { V } & 160 \\ 481 & \text { AAC } & \text { TCT } & \text { GAG } & \text { CAG } & \text { AGC } & \text { TCC } & \text { AGC } & \text { GTC } & \text { GAC } & \text { GAC } & \text { TTA } & \text { CTG } & \text { CTG } & \text { TGT } & \text { GAG } & \text { CCG } & \text { CCA ATC ATC ACA } & 540\end{array}$ $\begin{array}{llllllllllllllllllllll}161 & N & S & E & Q & S & S & S & V & D & D & L & L & L & C & E & P & P & I & \text { I } & T & 180\end{array}$ 541 GGC AGC CAA TCA CCT GTG CCG AAG AGC TTA GAG CCC GCC CAC CCT TCT TAT GAT GTC ATC 600 $\begin{array}{llllllllllllllllllllllll}181 & G & S & Q & S & P & V & P & K & S & \text { L } & \text { E } & \text { P } & \text { A } & \text { H } & \text { P } & \text { S } & \text { Y } & \text { D } & \text { V } & \text { I } & 200\end{array}$ 601 CAG TAT TAA

2010 Y $\frac{10}{*}$

C

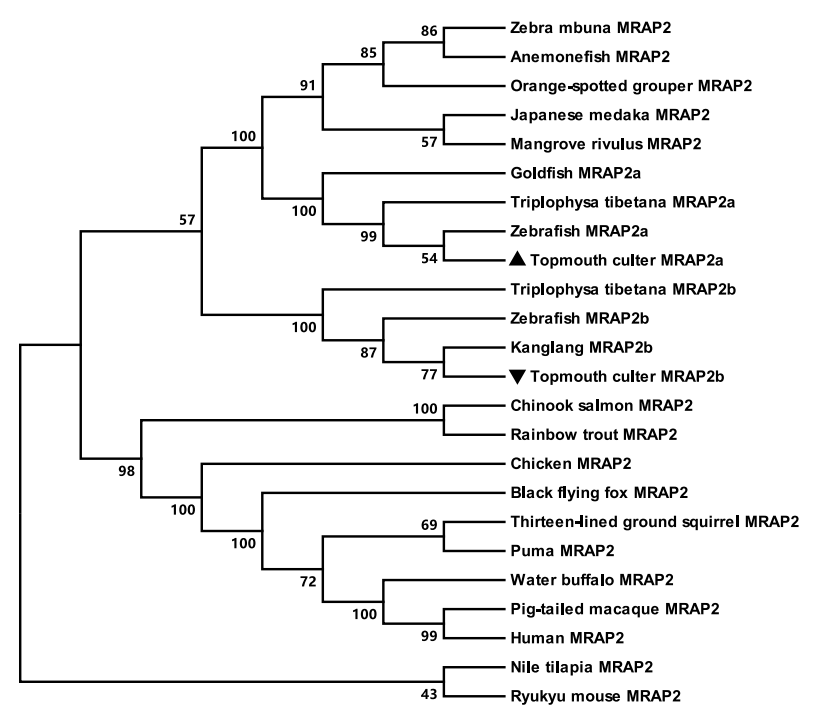

FIGURE 2 | Nucleotide and deduced amino acid sequences and phylogenetic tree of caMRAP2a and caMRAP2b. (A) Nucleotide and deduced amino acid sequences of caMRAP2a. (B) Nucleotide and deduced amino acid sequences of caMRAP2b. The positions of nucleotide and amino acid sequences are indicated on both sides. Shaded box shows putative TMD. Open boxes denote putative $N$-linked glycosylation sites. Underline show initiation and stop codons. Asterisk (*) indicates stop codon. (C) Phylogenetic tree of MRAP2s. The tree was constructed by the NJ method. Numbers at nodes indicate the bootstrap value, as percentages, obtained for 1,000 replicates. Black triangle dot show caMRAP2a and caMRAP2b. MRAP2s: Culter alburnus (topmouth culter, MRAP2a: MT163516, and MRAP2b: MT163517), Danio rerio (zebrafish, MRAP2a: F8W4H9.1, and MRAP2b: F8W4H9.1), Epinephelus coioides (orange-spotted grouper, QED39647.1), Oryzias latipes (Japanese medaka, XP_023809099.1), Maylandia zebra (zebra mbuna, XP_004568825.1), Amphiprion ocellaris (anemonefish, XP_023122806.1), Kryptolebias marmoratus (mangrove rivulus, XP_017267334.1), Oncorhynchus mykiss (rainbow trout, XP_021467183.1), Oreochromis niloticus (Nile tilapia, XP_003458293.2), Gallus gallus (chicken, ALO81626.1), Ictidomys tridecemlineatus (thirteen-lined ground squirrel, XP_021581743.1), Oncorhynchus tshawytscha (Chinook salmon, XP_024278413.1), Mus caroli (Ryukyu mouse, XP_021029091.1), Pteropus alecto (black flying fox, XP_006926405.1), Puma concolor (puma, XP_025781535.1), Homo sapiens (human, AAH10003.2), Bubalus bubalis (water buffalo, XP_006054803.2), Macaca nemestrina (pig-tailed macaque,

XP_011764298.1), Triplophysa tibetana (MRAP2a: KAA0703529.1 and MRAP2b: KAA0720858.1), Anabarilius grahami (Kanglang fish, MRAP2b ROJ29330.1), Carassius auratus (goldfish, MRAP2a: XP_026139519).

hypothalamus, medulla), pituitary gland, and the periphery (liver, testis, and head kidney) (Figure 3A). In the female culter, expression of $m c 4 r$ was higher in mesencephalon, olfactory bulb, telencephalon, hypothalamus, medulla, and pituitary gland, but expressed at low levels in other peripheral tissues (Figure 3B).

Culter mrap $2 a$ was highly expressed in brain, and moderately expressed in testis and ovary. Culter mrap $2 a$ was expressed more widely in peripheral tissues in female than in male
(Figures 3C,D). In the male, mrap2a was mainly expressed in testis and gill, and had a lower expression in other peripheral tissues studied (Figure 3C). In the female, mrap2a was present in liver, skin, kidney, gill, ovary, head kidney, and spleen (Figure 3D).

Similar to mrap $2 a$ distribution in the central nervous system, mrap $2 b$ was highly expressed in the olfactory bulb, telencephalon, cerebellum, mesencephalon, medulla, hypothalamus, and 


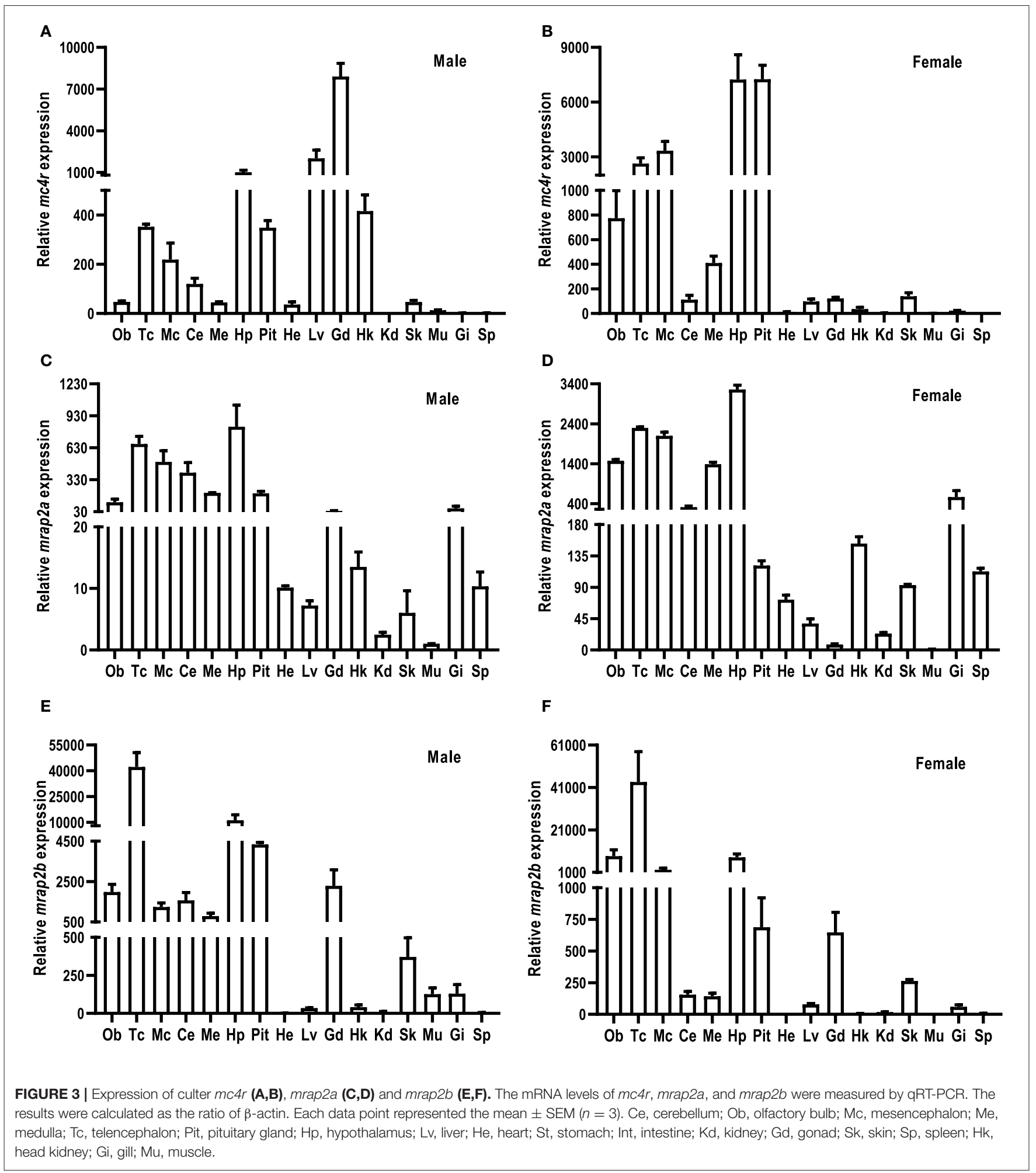

pituitary gland (Figures 3E,F). However, different from marp2a expression in peripheral tissues, mrap $2 b$ was present more widely in peripheral tissues of the male, including liver, head kidney, muscle, skin, testis, and gill (Figure 3E). In the female, mrap $2 b$ was primarily expressed in ovary and gill (Figure 3F). 


\section{Ligand Binding Properties of caMC4R}

Competitive ligand binding assays were performed to investigate the binding properties of caMC4R using hMC4R for comparison. Different concentrations of five unlabeled agonists (NDPMSH, $\alpha-\mathrm{MSH}, \beta-\mathrm{MSH}$, ACTH (1-24), and THIQ) were used as competitors with a fixed amount of ${ }^{125} \mathrm{I}-\mathrm{NDP}-\mathrm{MSH}$. The maximal binding values $\left(\mathrm{B}_{\max }\right)$ of caMC4R was $34.49 \pm 3.43 \%$ of that of the hMC4R (Figure 4 and Table 1). Similar as the binding affinity order of hMC4R, caMC4R bound to superpotent agonist NDP-MSH with the highest affinity $\left(\mathrm{IC}_{50}, 4.87 \pm\right.$ $1.80 \mathrm{nM})$, followed by ACTH $(1-24)(123.03 \pm 31.15 \mathrm{nM}), \alpha-$ MSH $(126.33 \pm 8.95 \mathrm{nM})$, and $\beta$-MSH $(442.00 \pm 65.43 \mathrm{nM})$ (Table 1). CaMC4R had a significantly higher affinity to $\beta$-MSH than hMC4R. THIQ was able to displace the ${ }^{125}$ I-NDP-MSH bound with caMC4R, although it had a lower affinity (1260.33 \pm $272.61 \mathrm{nM})$ compared with that for hMC4R $(164.63 \pm 30.15 \mathrm{nM})$ (Figure 4 and Table 1).

\section{Signaling Properties of caMC4R}

All agonists (NDP-MSH, $\alpha$-MSH, $\beta$-MSH, ACTH (1-24) and THIQ) were able to stimulate caMC4R and dose-dependently increased intracellular cAMP levels (Figure 5 and Table 2). Similar maximal responses $\left(\mathrm{R}_{\max }\right)$ and $\mathrm{EC}_{50}$ s to NDP-MSH, $\alpha$ $\mathrm{MSH}, \beta-\mathrm{MSH}$, and ACTH (1-24) stimulation were observed between caMC4R and hMC4R. However, $\mathrm{EC}_{50}$ was significantly increased and $R_{\max }$ was significantly decreased when stimulated by THIQ (Figure 5 and Table 2).

In this study, we found that the basal signaling of caMC4R was 4.08 times that of hMC4R (Table 2), indicating that caMC4R might be constitutively active. Different concentrations of caMC4R plasmid were transfected into cells and basal intracellular cAMP levels measured. We found that a low amount of caMC4R plasmid $(0.007 \mu \mathrm{g} / \mu \mathrm{L})$ transfected resulted in highlevel cAMP production (Figure 6A). Similar results were found in basal ERK1/2 phosphorylation, starting with a transfection
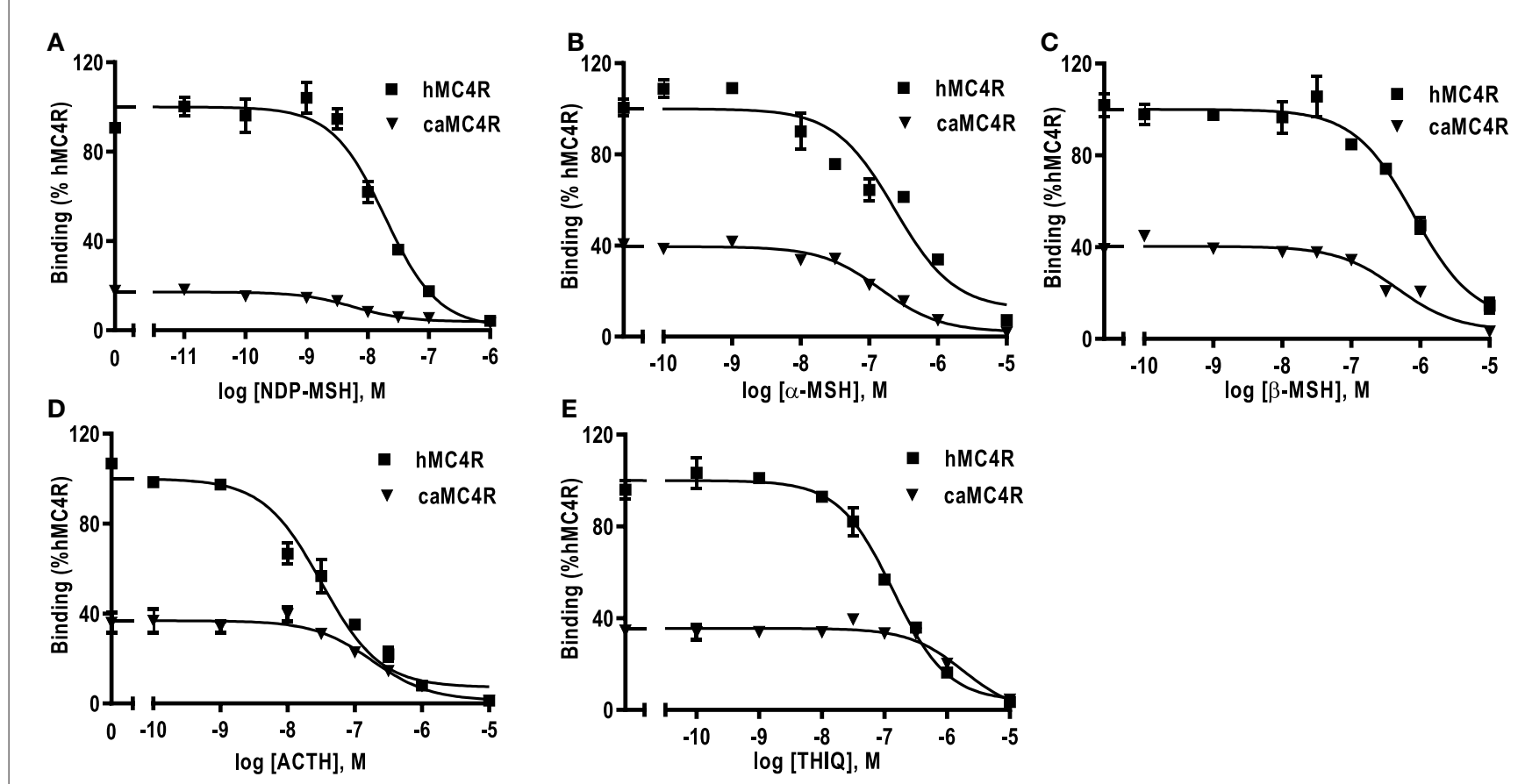

FIGURE 4 | Ligand binding properties of caMC4R. HEK293T cells were transiently transfected with caMC4R plasmids (hMC4R was used as a control). Different concentrations of unlabeled NDP-MSH (A), $\alpha-\mathrm{MSH}$ (B), $\beta-\mathrm{MSH}$ (C), ACTH (1-24) (D), and THIQ (E) was used to displace the binding of ${ }^{125}$ I-NDP-MSH. Results are expressed as $\%$ of hMC4R binding (in the absence of competitor) \pm range from duplicate determinations within one experiment. All experiment was repeated at least three times independently.

TABLE 1 | Ligand binding properties of caMC4R.

\begin{tabular}{|c|c|c|c|c|c|c|}
\hline MC4R & $\mathbf{B}_{\max } \%$ & NDP-MSH & $\alpha$-MSH & $\beta$-MSH & АСТH & THIQ \\
\hline caMC4R & $34.49 \pm 3.43^{b}$ & $4.87 \pm 1.80$ & $126.33 \pm 8.95$ & $442.00 \pm 65.43^{a}$ & $123.03 \pm 31.15$ & $1260.33 \pm 272.61$ \\
\hline
\end{tabular}

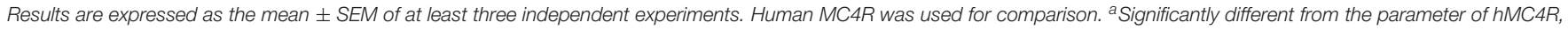
$P<0.05$. ${ }^{b}$ Significantly different from the parameter of $h M C 4 R, P<0.001$. 


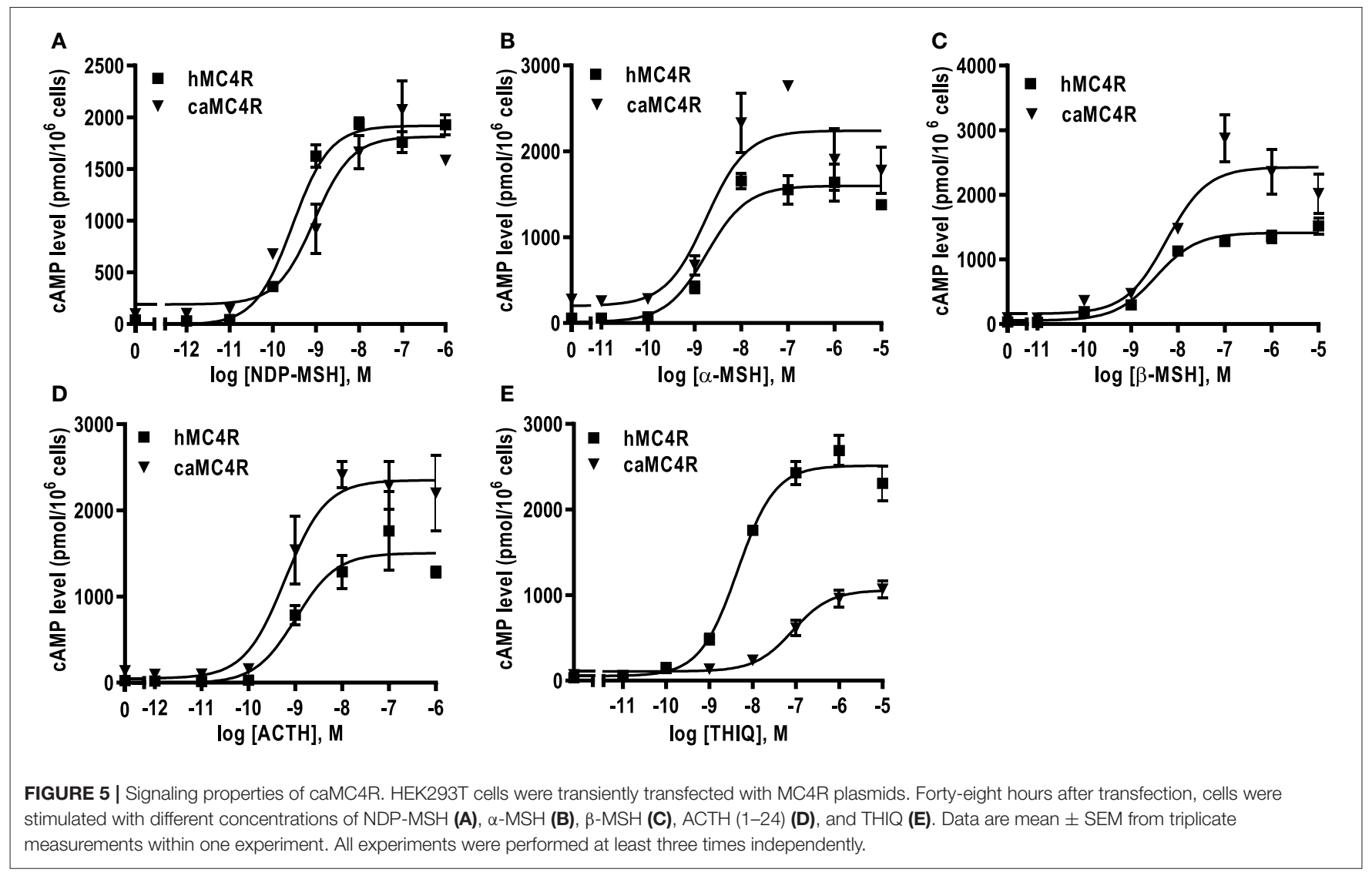

TABLE 2 | The signaling properties of hMC4R and caMC4R.

\begin{tabular}{lccc}
\hline MC4R & & caMC4R & hMC4R \\
\hline Basal (\%) & & $408.65 \pm 103.30^{\mathrm{a}}$ & 100 \\
NDP-MSH & $\mathrm{EC}_{50}(\mathrm{nM})$ & $0.44 \pm 0.24$ & $0.30 \pm 0.05$ \\
& $\mathrm{R}_{\max }(\%)$ & $84.48 \pm 8.28$ & 100 \\
$\alpha$-MSH & $\mathrm{EC}_{50}(\mathrm{nM})$ & $1.23 \pm 0.32$ & $1.16 \pm 0.32$ \\
& $\mathrm{R}_{\max }(\%)$ & $166.21 \pm 47.26$ & 100 \\
$\beta$-MSH & $\mathrm{EC}_{50}(\mathrm{nM})$ & $5.76 \pm 1.62$ & $3.91 \pm 1.09$ \\
& $\mathrm{R}_{\max }(\%)$ & $167.74 \pm 27.91$ & 100 \\
ACTH & $\mathrm{EC}_{50}(\mathrm{nM})$ & $1.60 \pm 0.76$ & $1.16 \pm 0.27$ \\
& $\mathrm{R}_{\max }(\%)$ & $149.21 \pm 26.94$ & 100 \\
THIQ & $\mathrm{EC}_{50}(\mathrm{nM})$ & $75.71 \pm 10.57^{\mathrm{a}}$ & $5.70 \pm 1.74$ \\
& $\mathrm{R}_{\max }(\%)$ & $39.73 \pm 1.37^{\mathrm{b}}$ & 100 \\
\hline
\end{tabular}

Results are expressed as the mean \pm SEM of at least three independent experiments. a Significantly different from the parameter of $h M C 4 R, P<0.01$.

${ }^{b}$ Significantly different from the parameter of $h M C 4 R, P<0.001$.

of $0.015 \mu \mathrm{g} / \mu \mathrm{L}$ caMC4R that significantly increased basal pERK1/2 level (Figures 6B,C). Therefore, our data indicated that caMC4R could be constitutively active in both cAMP and ERK1/2 pathways.

\section{Modulation of caMC4R Expression and Pharmacology by caMRAP2s}

The influence of caMRAP2a and caMRAP2b on the cell surface and total expression levels of caMC4R was performed by flow cytometry (Figure 7). The results demonstrated that caMRAP2a increased the cell surface and total expression of caMC4R, and there were no significant differences among groups (Figures 7A,B). Culter MRAP2b significantly increased cell surface and total expression of caMC4R in 1:3 group compared with the 1:0 group (Figures 7C,D).

Competitive ligand binding assays with $\operatorname{ACTH}(1-24)$ and $\alpha-$ MSH showed that caMRAP2a significantly increased the $\mathrm{B}_{\max }$ of caMC4R in the 1:5 group, while caMRAP2b did not affect the $\mathrm{B}_{\max }$ (Figures 8A,B and Table 3). CaMRAP2a and caMrAP2b significantly increased affinity of caMC4R to ACTH(1-24) but did not affect the $\mathrm{IC}_{50} \mathrm{~s}$ of caMC4R to $\alpha-\mathrm{MSH}$ (Table 3 ).

To study the effect of caMRAP2a or caMRAP2b on the cAMP signaling of caMC4R, cells were co-transfected with caMC4R/caMRAP2a or caMC4R/caMRAP2b in two different ratios (1:0 and 1:5) and ACTH (1-24) and $\alpha-\mathrm{MSH}$ were used as agonists. The results showed that caMRAP2a or caMRAP2b had no effect on $\mathrm{EC}_{50} \mathrm{~s}$; caMRAP2a significantly decreased the $\mathrm{R}_{\max }$, but caMRAP2b did not affect the $\mathrm{R}_{\max }$ (Figures $8 C, \mathrm{D}$ and Table 4).

We further investigated the dose-dependent effects of caMRAP2a or caMRAP2b on basal and maximal signaling to $\alpha$-MSH stimulation (Figure 9). Cells were co-transfected with four ratios of caMC4R/caMRAP2a or caMC4R/caMRAP2b (1:0, $1: 1,1: 3$, and 1:5). We found that the basal cAMP production of caMC4R were dose-dependently decreased by both caMRAP2a and caMRAP2b (Figures 9A,B). In addition, maximal cAMP 
A

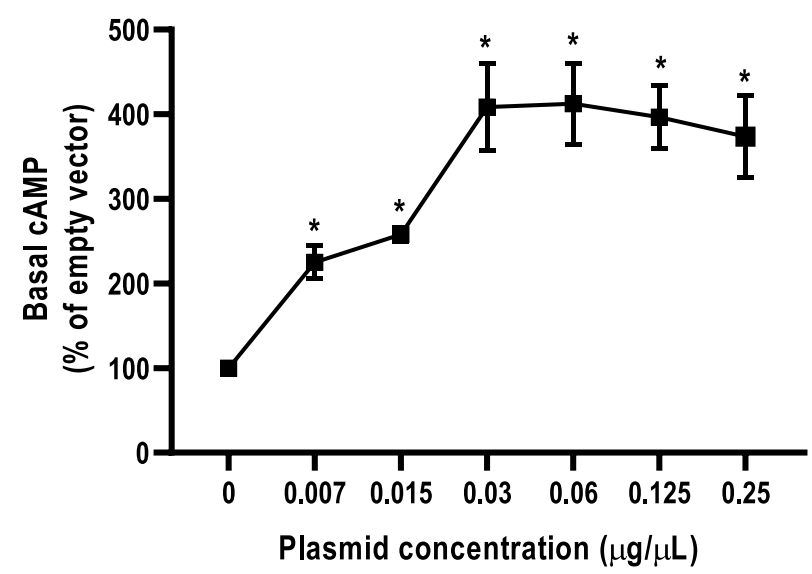

C

$\begin{array}{llllllll}\text { Plasmid }(\mu \mathrm{g} / \mu \mathrm{L}) & 0 & 0.007 & 0.015 & 0.030 & 0.060 & 0.125 & 0.250\end{array}$

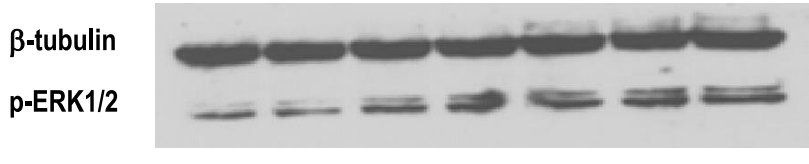

B

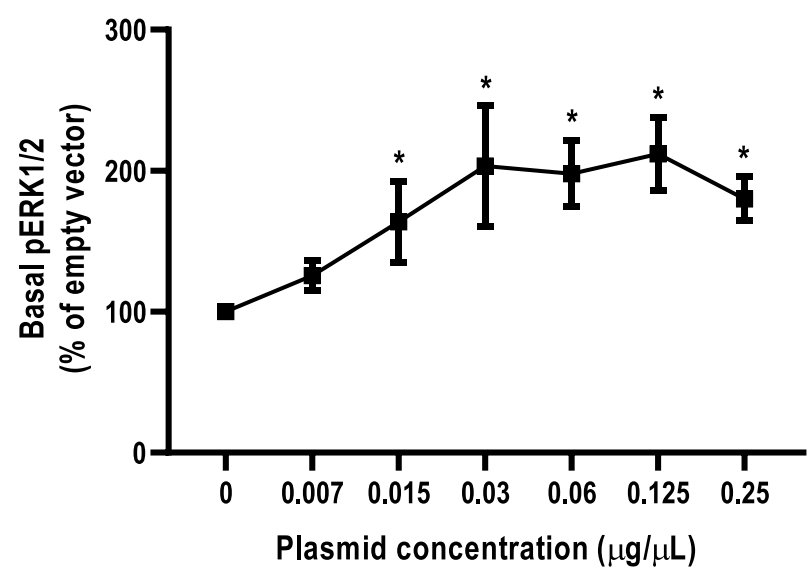

$55 \mathrm{kDa}$

$40 \mathrm{kDa}$

FIGURE 6 | Constitutive activities of caMC4R in CAMP and ERK1/2 pathways. HEK293T cells were transfected with increasing concentrations of caMC4R plasmids. Cells transfected with empty pcDNA3.1 vector was considered as control group. (A) cAMP levels were were measured by RIA. The curve was made with data from three independent experiments. (B,C) The ERK1/2 phosphorylation levels were detected by western blot. Values are expressed as mean \pm SEM $(n=3)$. Asterisk $\left(^{*}\right)$ showed significant difference of cAMP and pERK1/2 levels compared with control group $(P<0.05)$ (One-way ANOVA followed by Tukey-test).

levels of caMC4R activated by $10^{-6} \mathrm{M} \alpha-\mathrm{MSH}$ were also dosedependently decreased by caMRAP $2 \mathrm{a}$ in $1: 3$ and $1: 5$ groups but not caMRAP2b (Figures 9C,D).

\section{DISCUSSION}

In the present study, we demonstrated that cloned culter $m c 4 r$ was predicted to encode a protein of 326 amino acids with similar structural characteristics as MC4Rs of other species (Figure 1A and Supplementary Figure 2), including other teleost MC4Rs (27-31,37). Phylogenetic analysis revealed that caMC4R clustered with teleost MC4Rs (Figure 1B).

The distribution of MC4R in lower vertebrates is much wider than in mammals. We observed that culter mc4r was highly expressed in the central nervous system (Figure 3), consistent with it being a critical regulator of energy homeostasis $(7,24,28$, 30 ). In addition to brain, culter $m c 4 r$ was present more widely in the periphery in the male, especially in the testis (but not in the ovary) (Figures 3A,B). These data suggest that teleost MC4Rs might play an important role in regulating reproductive function $(28,30,37)$. Several studies have investigated the roles of teleost MC4R in regulating reproductive function (33, 35-37, 54, 55).

In the present study, we also cloned culter mrap $2 a$ and mrap $2 b$, and showed that similar to MRAP2s of other species, culter MRAP2a and MRAP2b had one potential $N$-linked glycosylation site in the N-terminal domain and a single highly conserved TMD (Figure 2 and Supplementary Figure 3).
Based on culter genomic data (43), we did not identify MRAP1 in topmouth culter, consistent with the hypothesis that MRAP1 is lost in lobe-finned fish, amphibians, and reptiles $(39,56)$. The tissue expression data showed that mrap $2 a$ and mrap $2 b$ were highly expressed in the central nervous system (Figures 3C-F), similar to the expression of $m c 4 r$, indicates that caMRAP2a or caMRAP2b might modulate MC4R signaling in the central nervous system. In the periphery, mrap $2 a$ was expressed more widely in the female than in the male, while mrap $2 b$ was expressed more widely in the male (Figures 3C-F). Especially, mrap $2 b$ was highly expressed in the testis and ovary, while mrap2a had lower expression in the testis and ovary (Figures 3C-F). These data suggested that caMRAP2a and caMRAP2b might have differential roles in modulating MC4R signaling in the periphery, especially in regulating gonadal function.

We also explored the pharmacology of the cloned caMC4R with binding and signaling assays. Our results showed that NDP-MSH bound to caMC4R with the highest affinity $\left(\mathrm{IC}_{50}\right.$ of $4.87 \mathrm{nM}$ ) and activated caMC4R with the highest potency $\left(\mathrm{EC}_{50}\right.$ was $0.44 \mathrm{nM}$ ) (Tables 1, 2). Lower binding capacity was observed in caMC4R (about 35\% of that of hMC4R) (Figure 4 and Table 1), consistent with previous studies in spotted scat (27), grass carp (28), swamp eel (29), sea bass (31), and orange-spotted grouper (30). In culter, ACTH had higher affinity and was more efficacious than $\alpha-\mathrm{MSH}$ for caMC4R, consistent with the suggestion that ACTH may be the original ligand for the MCRs (57). 

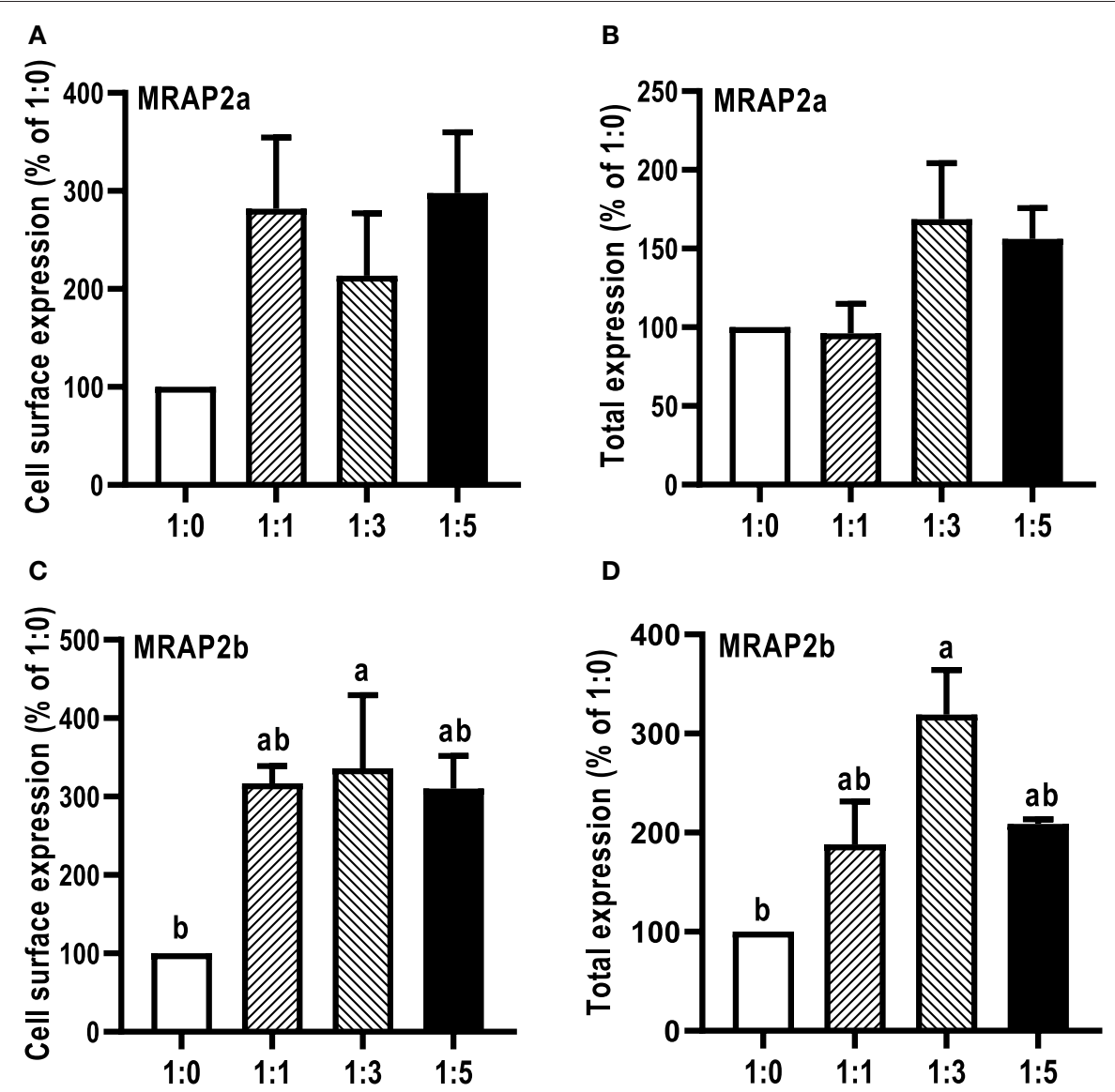

FIGURE 7 | Modulation of caMC4R expression by caMRAP2a or caMRAP2b. Cell surface (A,C) and total expression (B,D) of caMC4R was measured by flow cytometry. HEK293T cells were cotransfected with different ratios of caMC4R/caMRAP2a or caMC4R/caMRAP2b (1:0, 1:1, 1:3, and 1:5). The results were calculated as \% of 1:0 group after correction of the background staining (fluorescence in cells transfected with empty vector, pcDNA3.1). Each data point represented the mean \pm SEM $(n=3-4)$. Different letters indicated significant difference $(P<0.05)$ (One-way ANOVA followed by Tukey-test).

In cAMP signaling assay, $\alpha$-MSH, $\beta$-MSH and ACTH (1-24) stimulated caMC4R and hMC4R with similar potencies (Figure 5 and Table 2). THIQ, a small molecule agonist, displaced ${ }^{125} \mathrm{I}-$ NDP-MSH from caMC4R with a lower affinity than hMC4R (Table 1), activated caMC4R and initiated cAMP accumulation with an $\mathrm{EC}_{50}$ of $75.71 \mathrm{nM}(\sim 15$-fold higher than that of hMC4R) (Table 2). These data suggested that THIQ was not an allosteric agonist at caMC4R, different from our previous studies in grass carp and swamp eel $(28,29)$.

The hMC4R has been shown to have constitutive activity in Gs-cAMP signaling (58), and N-terminus is an important modulator in regulating constitutive activities in hMC4R (59). Mutations leading to decreased constitutive activity are associated with obesity pathogenesis $(6,59,60)$. Compared to hMC4R, teleost MC4Rs showed much higher constitutive activity in cAMP signaling (27-31). Our present study also showed that caMC4R significantly increased basal activities in Gs-cAMP and ERK1/2 signaling (Figure 6). The potential relevance of constitutive activity in teleost MC4Rs remains to be studied more extensively.
We further investigated whether MRAP2a and MRAP2b could modulate the trafficking, ligand binding and signaling of caMC4R. CaMRAP2a and caMRAP2b both increased the cell surface expression of caMC4R (Figure 7). In zebrafish, MRAP2b dose-dependently increases the cell surface expression of MC4R, while MRAP2a has no effect on the cell surface expression of MC4R (21). Mouse MRAP1 and MRAP2 decrease the cell surface expression of MC4R (20). In chicken, MRAP and MRAP2 have no significant effect the cell surface expression of MC4R (61). In tilapia, MRAP2 dose-dependently decreases the cell surface expression of MC4R (32). MRAP2 also decreases the cell surface expression of MCRa and MCRb in sea lamprey, which has only two MCRs (62). Therefore, the effect of MRAP2 on cell surface and total expression of the MC4R varies in different species. CaMRAP2a increased the $B_{\max }$ of caMC4R but caMRAP2b did not affect the $B_{\max }$ (Table 3 ). caMRAP2a and caMRAP2b significantly increased affinity of caMC4R to ACTH(1-24) but did not affect the $\mathrm{IC}_{50}$ of caMC4R to $\alpha-\mathrm{MSH}$ (Table 3 ).

Remarkably, culter MRAP2a and MRAP2b also inhibited the constitutive activity of caMC4R (Figure 9). Furthermore, 

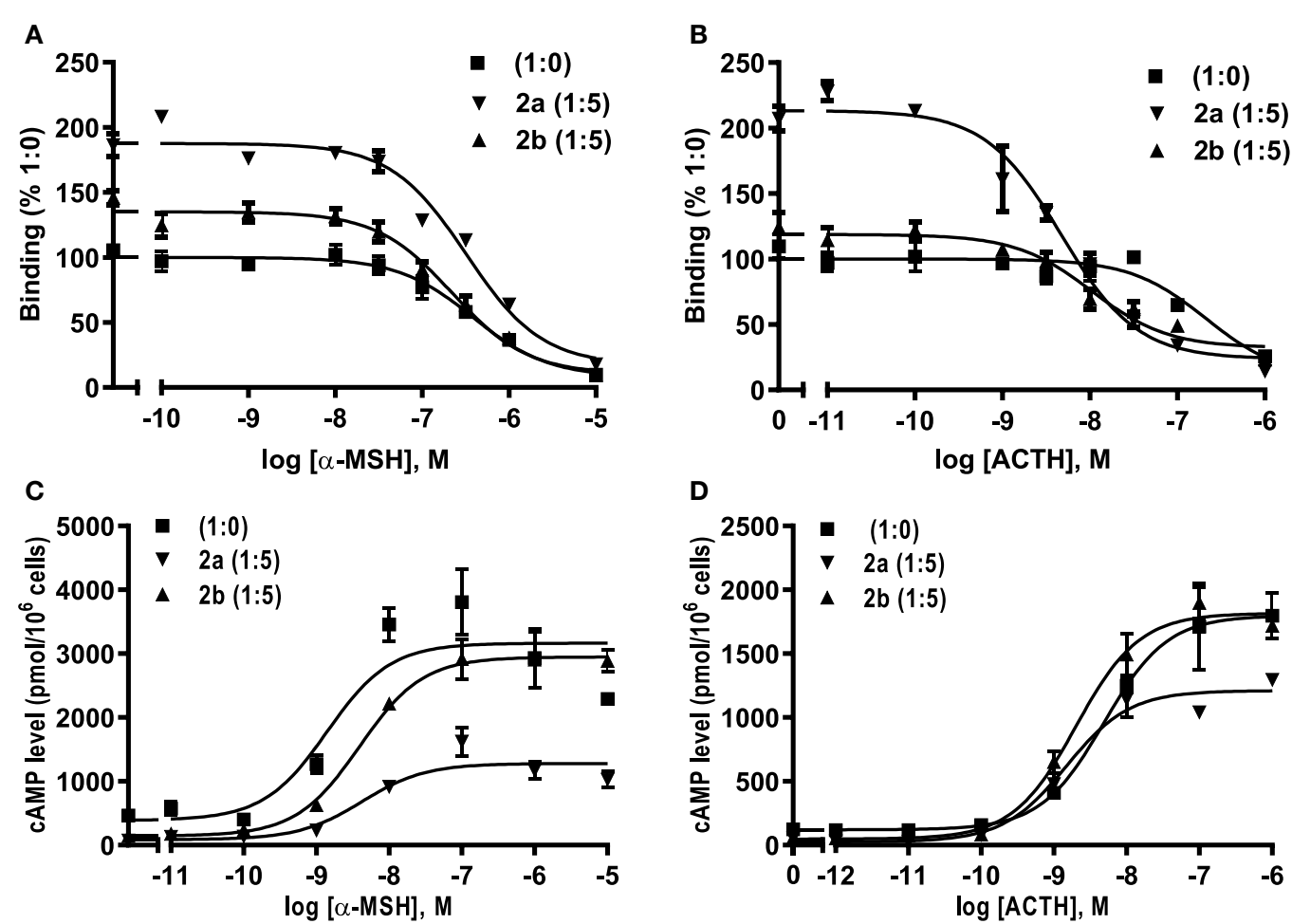

FIGURE 8 | Modulation of caMC4R pharmacology by caMRAP2a or caMRAP2b. Binding (A,B) and signaling properties (C,D) of caMC4R to $\alpha-$ MSH or ACTH (1-24) upon co-expression of caMRAP2a or caMRAP2b were measured. HEK293T cells were co-transfected with caMC4R/caMRAP2a or caMC4R/caMRAP2b in two different ratios (1:0, and 1:5). Binding and signaling properties were calculated as described in detail in Figures 4, 5, respectively.

TABLE 3 | The effect of caMRAP2a or caMRAP2b on ligand binding properties of caMC4R.

\begin{tabular}{lccr}
\hline $\begin{array}{l}\text { caMC4R/caMRAP2a or } \\
\text { caMRAP2b }\end{array}$ & $\mathbf{B}_{\max }$ & $\boldsymbol{\alpha}$-MSH & \multicolumn{1}{c}{ ACTH } \\
\cline { 3 - 4 } & & $\mathbf{I C}_{\mathbf{5 0}}$ (nM) & $\mathbf{I C}_{50}$ (nM) \\
\hline caMC4R (1:0) & 100 & $229.00 \pm 79.70$ & $235.13 \pm 16.70$ \\
caMC4R/caMRAP2a (1:5) & $170.74 \pm 13.08^{\mathrm{a}}$ & $233.07 \pm 44.80$ & $6.34 \pm 1.07^{\mathrm{a}}$ \\
caMC4R/caMRAP2b (1:5) & $123.58 \pm 9.86$ & $153.47 \pm 33.83$ & $10.43 \pm 1.12^{\mathrm{a}}$ \\
\hline
\end{tabular}

Results are expressed as the mean \pm SEM of at least three independent experiments. a Significantly different from the parameter of 1:0, $P<0.001$.

caMRAP2a significantly decreased the $R_{\max }$ but caMRAP2b had no effect on the $R_{\max }$ (Table 4). MRAP2 decreases the constitutive activity of MC4R and the $\mathrm{R}_{\max }$ of MC4R in tilapia and grouper $(30,32)$. In zebrafish, MRAP2a suppresses the constitutive activity of MC4R, reduces the $\mathrm{R}_{\max }$, while increases $\alpha-\mathrm{MSH}$ potency and MRAP2b suppresses the constitutive activity of MC4R and increases the $\mathrm{R}_{\max }$ (21). In sea lamprey, MRAP2 increases agonist-stimulated signaling of MCRa and MCRb (62). In chicken, MRAP and MRAP2 decreases the basal activity and increases sensitivity to ACTH (61). In mouse, MRAP1 and MRAP2 decreases agonist-stimulated cAMP production (20). Therefore, different effects of MRAPs on
TABLE 4 | The effect of caMRAP2a or caMRAP2b on CAMP signaling properties of caMC4R.

\begin{tabular}{|c|c|c|c|c|}
\hline \multirow{2}{*}{$\begin{array}{l}\text { caMC4R/caMRAP2a } \\
\text { or } \\
\text { caMRAP2b }\end{array}$} & \multicolumn{2}{|c|}{$\alpha-\mathbf{M S H}$} & \multicolumn{2}{|c|}{ АCTH } \\
\hline & $\mathrm{EC}_{50}(\mathrm{nM})$ & $\mathbf{R}_{\max }$ & $\mathrm{EC}_{50}(\mathrm{nM})$ & $\mathbf{R}_{\max }$ \\
\hline caMC4R (1:0) & $1.53 \pm 0.15$ & 100 & $3.63 \pm 1.21$ & 100 \\
\hline $\begin{array}{l}\text { caMC4R/caMRAP2a } \\
(1: 5)\end{array}$ & $5.93 \pm 1.73$ & $47.60 \pm 7.94^{\mathrm{a}}$ & $1.29 \pm 0.34$ & $60.18 \pm 3.62^{a}$ \\
\hline $\begin{array}{l}\text { caMC4R/caMRAP2b } \\
(1: 5)\end{array}$ & $4.76 \pm 1.13$ & $85.21 \pm 5.27$ & $1.75 \pm 0.15$ & $98.86 \pm 4.02$ \\
\hline
\end{tabular}

Results are expressed as the mean $\pm S E M$ of at least three independent experiments. ${ }^{a}$ Significantly different from the parameter of 1:0, $P<0.001$.

MC4R basal and agonist-stimulated signaling are observed in different species.

One shortcoming of this study is that we used human $\mathrm{ACTH}$ and $\beta$-MSH for the experiments. $\alpha-\mathrm{MSH}$ has been shown to be fully conserved in all species with POMC gene studied so far, including culter investigated here. For ACTH(124), there were 3 amino acids different between human and culter sequences, but two of these changes were very conservative (Supplementary Figure 1). Therefore, we deduce that culter ACTH(1-24) would likely behave similarly as human $\operatorname{ACTH}(1-24)$ that we used in the experiments. There was 

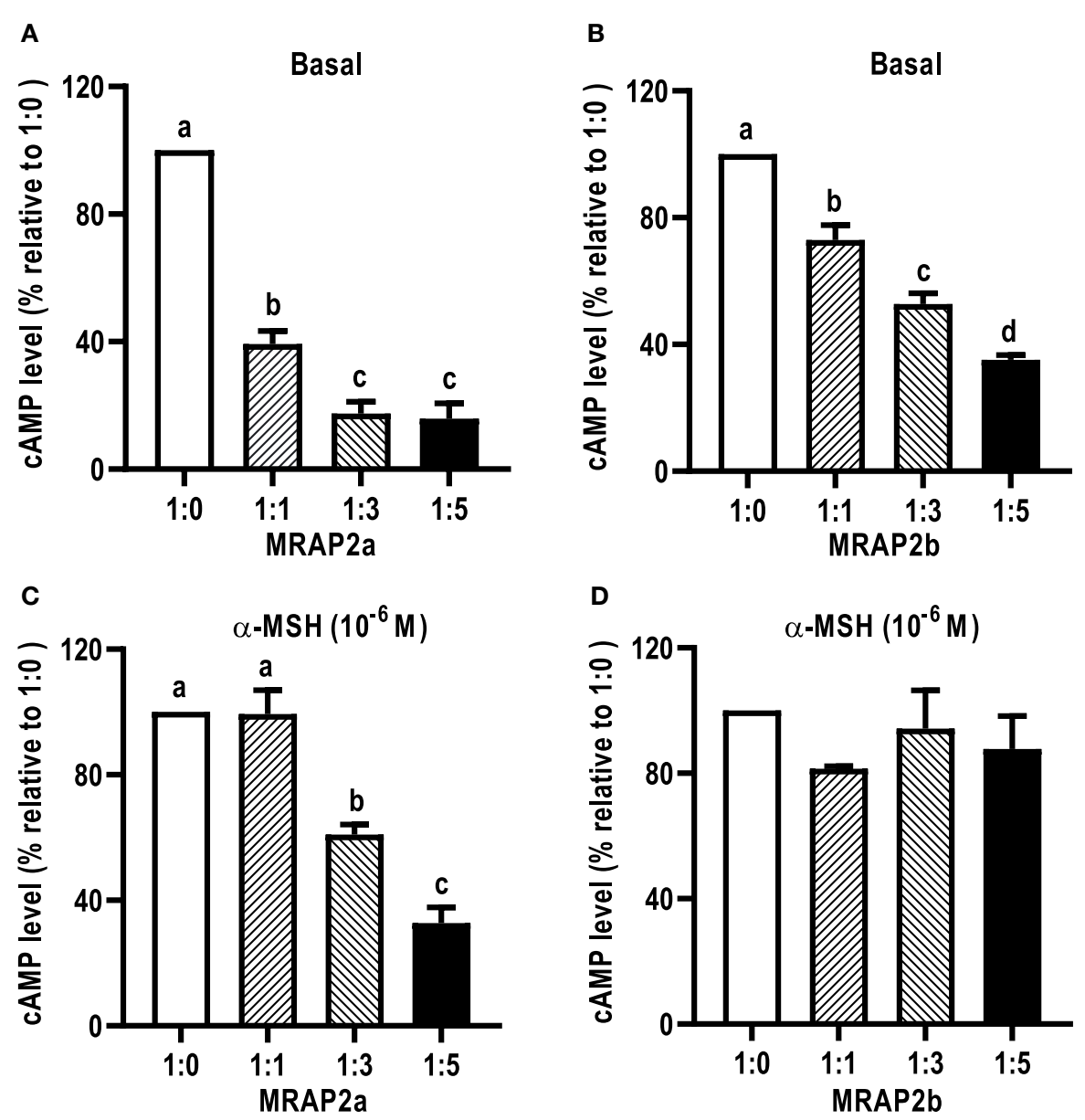

FIGURE 9 | The effects of caMRAP2a or caMRAP2b on caMC4R signaling. HEK293T cells were co-transfected with different ratios of caMC4R/caMRAP2a or caMC4R/caMRAP2b (1:0, 1:1, 1:3, and 1:5) and cAMP levels under basal (A,B) or stimulated [with 10-6 $\mathbf{M} \alpha-\mathbf{M S H}$, (C,D)] conditions were measured. Data are expressed as \% of 1:0 group. Values are expressed as mean \pm SEM $(n=3)$. Different letters indicate significant difference (one-way ANOVA followed by Tukey-test).

only $57.1 \%$ homology between human and culter $\beta$-MSHs (Supplementary Figure 1). Therefore, we need to interpret the data obtained for $\beta$-MSH with caution. In future studies, we need to identify the molecular forms of the endogenous MSHs produced and the modifications (for example, acetylated or des-acetylated) and synthesize these peptides for functional characterization experiments.

In summary, we cloned and analyzed the expression patterns of $m c 4 r, m r a p 2 a$, and $m r a p 2 b$ from topmouth culter. All three genes were mainly present in the central nervous system, but differential expression was observed in the periphery. Culter MC4R had high constitutive activities and similar potencies to several agonists as hMC4R. Culter MRAP2a significantly increased the $B_{\max }$ and decreased agonist-stimulated cAMP, whereas culter MRAP2b increased the cell surface and total expression but did not affect $\mathrm{B}_{\max }$ and agonist-stimulated cAMP. Therefore, these data suggested that caMRAP2a and caMRAP2b had differential effects on the expression, binding, and signaling of caMC4R. These findings lay the foundation for future physiological studies on the functions of culter MC4R that might provide new strategies to improve growth and reproduction in culter culture.

\section{DATA AVAILABILITY STATEMENT}

The raw data supporting the conclusions of this article will be made available by the authors, without undue reservation.

\section{ETHICS STATEMENT}

The animal study was reviewed and approved by Animal Care Committee of Hunan Normal University.

\section{AUTHOR CONTRIBUTIONS}

MT: conceptualization, investigation, writing original draft, and funding acquisition. R-LJ: conceptualization, investigation, and writing original draft. LH, S-YF, and TL: investigation. S-JL and Y-XT: conceptualization, writing-review and editing, supervision, project administration, and funding acquisition. 
All authors contributed to the article and approved the submitted version.

\section{FUNDING}

This research was supported by the National Natural Science Foundation of China (Grant Nos. 31872551, U19A2040, and 31730098), the earmarked fund for China Agriculture Research System (Grant No. CARS-45), and 111 Project (D20007). This study was also partially supported by Animal Health

\section{REFERENCES}

1. Smith AI, Funder JW. Proopiomelanocortin processing in the pituitary, central nervous system, and peripheral tissues. Endocr Rev. (1988) 9:159-79. doi: 10.1210/edrv-9-1-159

2. Dores RM, Lecaude S. Trends in the evolution of the proopiomelanocortin gene. Gen Comp Endocrinol. (2005) 142:81-93. doi: 10.1016/j.ygcen.2005.02.003

3. Gantz I, Fong TM. The melanocortin system. Am J Physiol Endocrinol Metab. (2003) 284:E468-74. doi: 10.1152/ajpendo.00434.2002

4. Cone RD. Studies on the physiological functions of the melanocortin system. Endocr Rev. (2006) 27:736-49. doi: 10.1210/er.2006-0034

5. Tao YX. Melanocortin receptors. Biochim Biophys Acta. (2017) 1863:2411-3. doi: 10.1016/j.bbadis.2017.08.001

6. Tao YX. Molecular mechanisms of the neural melanocortin receptor dysfunction in severe early onset obesity. Mol Cell Endocrinol. (2005) 239:114. doi: 10.1016/j.mce.2005.04.012

7. Tao YX. The melanocortin-4 receptor: physiology, pharmacology, and pathophysiology. Endocr Rev. (2010) 31:506-43. doi: 10.1210/er.2009-0037

8. Huszar D, Lynch CA, Fairchild-Huntress V, Dunmore JH, Fang Q, Berkemeier LR, et al. Targeted disruption of the melanocortin- 4 receptor results in obesity in mice. Cell. (1997) 88:131-41. doi: 10.1016/S0092-8674(00)81865-6

9. Balthasar N, Dalgaard LT, Lee CE, Yu J, Funahashi H, Williams T, et al. Divergence of melanocortin pathways in the control of food intake and energy expenditure. Cell. (2005) 123:493-505. doi: 10.1016/j.cell.2005.08.035

10. Farooqi IS, Keogh JM, Yeo GS, Lank EJ, Cheetham T, O'rahilly S. Clinical spectrum of obesity and mutations in the melanocortin 4 receptor gene. $N$ Engl J Med. (2003) 348:1085-95. doi: 10.1056/NEJMoa022050

11. Tao YX. Mutations in melanocortin-4 receptor and human obesity. Prog Mol Biol Transl Sci. (2009) 88:173-204. doi: 10.1016/S1877-1173(09)88006-X

12. Hinney A, Volckmar AL, Knoll N. Melanocortin-4 receptor in energy homeostasis and obesity pathogenesis. Prog Mol Biol Transl Sci. (2013) 114:147-11. doi: 10.1016/B978-0-12-386933-3.00005-4

13. Gantz I, Konda Y, Tashiro T, Shimoto Y, Miwa H, Munzert G, et al. Molecular cloning of a novel melanocortin receptor. J Biol Chem. (1993) 268:8246-50.

14. Daniels D, Patten CS, Roth JD, Yee DK, Fluharty SJ. Melanocortin receptor signaling through mitogen-activated protein kinase in vitro and in rat hypothalamus. Brain Res. (2003) 986:1-11. doi: 10.1016/S0006-8993(03)03162-7

15. Vongs A, Lynn NM, Rosenblum CI. Activation of MAP kinase by MC4-R through PI3 kinase. Regul Pept. (2004) 120:113-8. doi: 10.1016/j.regpep.2004.02.018

16. Huang $\mathrm{H}$, Tao YX. Pleiotropic functions of the transmembrane domain 6 of human melanocortin-4 receptor. J Mol Endocr. (2012) 49:237-48. doi: 10.1530/JME-12-0161

17. Mo XL, Yang R, Tao YX. Functions of transmembrane domain 3 of human melanocortin-4 receptor. J Mol Endocrinol. (2012) 49:221-35. doi: 10.1530/JME-12-0162

18. Metherell LA, Chapple JP, Cooray S, David A, Becker C, Ruschendorf F, et al. Mutations in MRAP, encoding a new interacting partner of the ACTH receptor, cause familial glucocorticoid deficiency type 2. Nat Genet. (2005) 37:166-70. doi: 10.1038/ng1501 and Disease Research Program of College of Veterinary Medicine at Auburn University. MT, R-LJ, and TL received fellowships from China Scholarship Council, People's Republic of China.

\section{SUPPLEMENTARY MATERIAL}

The Supplementary Material for this article can be found online at: https://www.frontiersin.org/articles/10.3389/fendo. 2020.00538/full\#supplementary-material

19. Sebag JA, Hinkle PM. Melanocortin-2 receptor accessory protein MRAP forms antiparallel homodimers. Proc Natl Acad Sci USA. (2007) 104:20244-9. doi: 10.1073/pnas.0708916105

20. Chan LF, Webb TR, Chung TT, Meimaridou E, Cooray SN, Guasti $\mathrm{L}$, et al. MRAP and MRAP2 are bidirectional regulators of the melanocortin receptor family. Proc Natl Acad Sci USA. (2009) 106:6146-51. doi: 10.1073/pnas.0809918106

21. Sebag JA, Zhang C, Hinkle PM, Bradshaw AM, Cone RD. Developmental control of the melanocortin-4 receptor by MRAP2 proteins in zebrafish. Science. (2013) 341:278-81. doi: 10.1126/science.1232995

22. Asai M, Ramachandrappa S, Joachim M, Shen Y, Zhang R, Nuthalapati $\mathrm{N}$, et al. Loss of function of the melanocortin 2 receptor accessory protein 2 is associated with mammalian obesity. Science. (2013) 341:275-8. doi: $10.1126 /$ science. 1233000

23. Schonnop L, Kleinau G, Herrfurth N, Volckmar AL, Cetindag C, Müller A, et al. Decreased melanocortin- 4 receptor function conferred by an infrequent variant at the human melanocortin receptor accessory protein 2 gene. Obesity. (2016) 24:1976-82. doi: 10.1002/oby.21576

24. Cerdá-Reverter JM, Ringholm A, Schioth HB, Peter RE. Molecular cloning, pharmacological characterization, and brain mapping of the melanocortin 4 receptor in the goldfish: involvement in the control of food intake. Endocrinology. (2003) 144:2336-49. doi: 10.1210/en.2002-0213

25. Song Y, Cone RD. Creation of a genetic model of obesity in a teleost. FASEB J. (2007) 21:2042-9. doi: 10.1096/fj.06-7503com

26. Wei R, Yuan D, Zhou C, Wang T, Lin F, Chen H, et al. Cloning, distribution and effects of fasting status of melanocortin 4 receptor (MC4R) in Schizothorax prenanti. Gene. (2013) 532:10017. doi: 10.1016/j.gene.2013.09.068

27. Li JT, Yang Z, Chen HP, Zhu CH, Deng SP, Li GL, et al. Molecular cloning, tissue distribution, and pharmacological characterization of melanocortin-4 receptor in spotted scat, Scatophagus argus. Gen Comp Endocrinol. (2016) 230-231:143-52. doi: 10.1016/j.ygcen.2016.04.010

28. Li L, Yang Z, Zhang YP, He S, Liang XF, Tao YX. Molecular cloning, tissue distribution, and pharmacological characterization of melanocortin-4 receptor in grass carp (Ctenopharyngodon idella). Domest Anim Endocrinol. (2017) 59:140-51. doi: 10.1016/j.domaniend.2016.11.004

29. Yi TL, Yang LK, Ruan GL, Yang DQ, Tao YX. Melanocortin-4 receptor in swamp eel (Monopterus albus): cloning, tissue distribution, and pharmacology. Gene. (2018) 678:79-89. doi: 10.1016/j.gene.2018.07.056

30. Rao YZ, Chen R, Zhang Y, Tao YX. Orange-spotted grouper melanocortin-4 receptor: modulation of signaling by MRAP2. Gen Comp Endocrinol. (2019) 284:113234. doi: 10.1016/j.ygcen.2019.113234

31. Zhang KQ, Hou ZS, Wen HS, Li Y, Qi X, Li WJ, et al. Melanocortin4 receptor in spotted sea bass, Lateolabrax maculatus: Cloning, tissue distribution, physiology, and pharmacology. Front Endocrinol. (2019) 10:705. doi: 10.3389/fendo.2019.00705

32. Wang M, Chen YJ, Zhu M, Xu BX, Guo WX, Lyu YS, et al. Pharmacological modulation of melanocortin-4 receptor by melanocortin receptor accessory protein 2 in Nile tilapia. Gen Comp Endocrinol. (2019) 282:113219. doi: 10.1016/j.ygcen.2019.113219

33. Lampert KP, Schmidt C, Fischer P, Volff JN, Hoffmann C, Muck J, et al. Determination of onset of sexual maturation and mating behavior by 
melanocortin receptor 4 polymorphisms. Curr Biol. (2010) 20:1729-34. doi: 10.1016/j.cub.2010.08.029

34. Aspiras AC, Rohner N, Martineau B, Borowsky RL, Tabin CJ. Melanocortin 4 receptor mutations contribute to the adaptation of cavefish to nutrient-poor conditions. Proc Natl Acad Sci USA. (2015) 112:9668-73. doi: 10.1073/pnas.1510802112

35. Smith CC, Harris RM, Lampert KP, Schartl M, Hofmann HA, Ryan MJ. Copy number variation in the melanocortin 4 receptor gene and alternative reproductive tactics the swordtail Xiphophorus multilineatus. Environ Biol Fishes. (2015) 98:23-33. doi: 10.1007/s10641-014-0234-y

36. Jiang DN, Li JT, Tao YX, Chen HP, Deng SP, Zhu CH, et al. Effects of melanocortin-4 receptor agonists and antagonists on expression of genes related to reproduction in spotted scat, Scatophagus argus. J Comp Physiol B. (2017) 187:603-12. doi: 10.1007/s00360-017-1062-0

37. Zhang Y, Wen HS, Li Y, Lyu LK, Zhang ZX, Wang XJ, et al. Melanocortin4 receptor regulation of reproductive function in black rockfish (Sebastes schlegelii). Gene. (2020) 741:144541. doi: 10.1016/j.gene.2020.144541

38. Västermark $\AA$, Schiöth HB. The early origin of melanocortin receptors, agouti-related peptide, agouti signalling peptide, and melanocortin receptor-accessory proteins, with emphasis on pufferfishes, elephant shark, lampreys, and amphioxus. Eur J Pharmacol. (2011) 660:61-9. doi: 10.1016/j.ejphar.2010.10.106

39. Valsalan R, Krishnan A, Almen MS, Fredriksson R, Schioth HB. Early vertebrate origin of melanocortin 2 receptor accessory proteins (MRAPs). Gen Comp Endocrinol. (2013) 188:123-32. doi: 10.1016/j.ygcen.2013.01.004

40. Josep Agulleiro M, Cortes R, Fernandez-Duran B, Navarro S, Guillot R, Meimaridou E, et al. Melanocortin 4 receptor becomes an ACTH receptor by coexpression of melanocortin receptor accessory protein 2. Mol Endocrinol. (2013) 27:1934-45. doi: 10.1210/me.2013-1099

41. Chen YY. Fauna Sinica Osteichthyes Cypriniformes II. Beijing: Science Press (1998).

42. Cao XJ, Wang WM. Haematological and biochemical characteristics of two aquacultured carnivorous cyprinids, topmouth culter Culter alburnus (Basilewsky) and yellowcheek carp Elopichthys bambusa (Richardson). Aquaculture Res. (2010) 41:1331-8. doi: 10.1111/j.1365-2109.2009.02421.x

43. Ren L, Li WH, Qin QB, Dai H, Han FM, Xiao J, et al. The subgenomes show asymmetric expression of alleles in hybrid lineages of Megalobrama amblycephala x Culter alburnus. Genome Res. (2019) 29:180515. doi: 10.1101/gr.249805.119

44. Ren L, Tan XJ, Xiong YF, Xu K, Zhou Y, Zhong H, et al. Transcriptome analysis reveals positive selection on the divergent between topmouth culter and zebrafish. Gene. (2014) 552:265-71. doi: 10.1016/j.gene.2014.09.053

45. Wang W, Chen LQ, Yang P, Hou L, He CB, Gu ZM, et al. Assessing genetic diversity of populations of topmouth culter (Culter alburnus) in China using AFLP markers. Biochem System Ecol. (2007) 35:662-9. doi: 10.1016/j.bse.2007.04.008

46. Sebhat IK, Martin WJ, Ye Z, Barakat K, Mosley RT, Johnston DB, et al. Design and pharmacology of $\mathrm{N}$-[(3R)-1,2,3,4-tetrahydroisoquinolinium3-ylcarbonyl]-(1R)-1-(4-chlorobenzyl)- 2-[4-cyclohexyl-4-(1H-1,2,4-triazol1-ylmethyl)piperidin-1-yl]-2-oxoethylamine (1), a potent, selective, melanocortin subtype-4 receptor agonist. J Med Chem. (2002) 45:4589-93. doi: 10.1021/jm025539h

47. Steiner AL, Kipnis DM, Utiger R, Parker C. Radioimmunoassay for the measurement of adenosine 3',5'-cyclic phosphate. Proc Natl Acad Sci USA. (1969) 64:367-73. doi: 10.1073/pnas.64.1.367

48. Tao YX, Segaloff DL. Functional characterization of melanocortin-4 receptor mutations associated with childhood obesity. Endocrinology. (2003) 144:454451. doi: 10.1210/en.2003-0524
49. Livak KJ, Schmittgen TD. Analysis of relative gene expression data using realtime quantitative PCR and the $2^{-\Delta \Delta C T}$ method. Methods. (2001) 25:402-8. doi: $10.1006 /$ meth.2001.1262

50. Chen C, Okayama H. High-efficiency transformation of mammalian cells by plasmid DNA. Mol Cell Biol. (1987) 7:2745-52. doi: 10.1128/MCB.7.8.2745

51. Wang SX, Fan ZC, Tao YX. Functions of acidic transmembrane residues in human melanocortin-3 receptor binding and activation. Biochem Pharmacol. (2008) 76:520-30. doi: 10.1016/j.bcp.2008.05.026

52. Yang LK, Zhang ZR, Wen HS, Tao YX. Characterization of channel catfish (Ictalurus punctatus) melanocortin-3 receptor reveals a potential network in regulation of energy homeostasis. Gen Comp Endocrinol. (2019) 277:90-103. doi: 10.1016/j.ygcen.2019.03.011

53. Sebag JA, Hinkle PM. Opposite effects of the melanocortin-2 (MC2) receptor accessory protein MRAP on MC2 and MC5 receptor dimerization and trafficking. J Biol Chem. (2009) 284:22641-8. doi: 10.1074/jbc.M109.022400

54. Volff JN, Selz Y, Hoffmann C, Froschauer A, Schultheis C, Schmidt C, et al. Gene amplification and functional diversification of melanocortin 4 receptor at an extremely polymorphic locus controlling sexual maturation in the platyfish. Genetics. (2013) 195:1337-52. doi: 10.1534/genetics.113.155952

55. Liu RQ, Du K, Ormanns J, Adolfi MC, Schartl M. Melanocortin 4 receptor signaling and puberty onset regulation in Xiphophorus swordtails. Gen Comp Endocrinol. (2020) 295:113521. doi: 10.1016/j.ygcen.2020.113521

56. Tao YX. Molecular chaperones and G protein-coupled receptor maturation and pharmacology. Mol Cell Endocrinol. (2020) 511:110862. doi: $10.1016 /$ j.mce.2020.110862

57. Metz JR, Peters JJ, Flik G. Molecular biology and physiology of the melanocortin system in fish: a review. Gen Comp Endocrinol. (2006) 148:15062. doi: 10.1016/j.ygcen.2006.03.001

58. Tao YX. Constitutive activity in melanocortin-4 receptor: biased signaling of inverse agonists. Adv Pharmacol. (2014) 70:135-54. doi: 10.1016/B978-0-12-417197-8.00005-5

59. Srinivasan S, Lubrano-Berthelier C, Govaerts C, Picard F, Santiago P, Conklin BR, et al. Constitutive activity of the melanocortin-4 receptor is maintained by its $\mathrm{N}$-terminal domain and plays a role in energy homeostasis in humans. J Clin Invest. (2004) 114:1158-64. doi: 10.1172/JCI2004 21927

60. Tao YX. Constitutive activation of $G$ protein-coupled receptors and diseases: insights into mechanism of activation and therapeutics. Pharmacol Ther. (2008) 120:129-48. doi: 10.1016/j.pharmthera.2008. 07.005

61. Zhang J, Li X, Zhou Y, Cui L, Li J, Wu C, et al. The interaction of MC3R and MC4R with MRAP2, ACTH, $\alpha-\mathrm{MSH}$ and AgRP in chickens. J Endocrinol. (2017) 234:155-74. doi: 10.1530/JOE-17-0131

62. Zhu M, Xu B, Wang M, Liu S, Zhang Y, Zhang C. Pharmacological modulation of MRAP2 protein on melanocortin receptors in the sea lamprey. Endocr Connect. (2019) 8:378-88. doi: 10.1530/EC-19-0019

Conflict of Interest: The authors declare that the research was conducted in the absence of any commercial or financial relationships that could be construed as a potential conflict of interest.

Copyright (C) 2020 Tao, Ji, Huang, Fan, Liu, Liu and Tao. This is an open-access article distributed under the terms of the Creative Commons Attribution License (CC $B Y)$. The use, distribution or reproduction in other forums is permitted, provided the original author(s) and the copyright owner(s) are credited and that the original publication in this journal is cited, in accordance with accepted academic practice. No use, distribution or reproduction is permitted which does not comply with these terms. 